OPEN ACCESS

Edited by:

Juarez Antonio Simões Quaresma,

Evandro Chagas Institute, Brazil

Reviewed by:

Shamik Majumdar,

National Institute of Allergy and

Infectious Diseases $(\mathrm{NIH})$,

United States

Rong Jin,

Peking University, China

Rachel Thomas,

University of North Texas Health

Science Center, United States

Weikan Wang

University of North Texas Health

Science Center, United States

*Correspondence:

$X i$ Sun

sunxi2@mail.sysu.edu.cn

${ }^{+}$These authors have contributed equally to this work and share first authorship

Specialty section: This article was submitted to Microbial Immunology, a section of the journal

Frontiers in Immunology

Received: 12 January 2021 Accepted: 07 May 2021 Published: 25 May 2021

Citation:

Luo M, Xu L, Qian Z and Sun X (2021) Infection-Associated Thymic Atrophy.

Front. Immunol. 12:652538.

doi: 10.3389/fimmu.2021.652538

\section{Infection-Associated Thymic Atrophy}

\author{
Mingli Luo ${ }^{1,2,3 \dagger}$, Lingxin Xu ${ }^{1,2,3 \dagger}$, Zhengyu Qian ${ }^{1,2,3 \dagger}$ and Xi Sun ${ }^{1,2,3 *}$ \\ ${ }^{1}$ Department of Parasitology of Zhongshan School of Medicine, Sun Yat-sen University, Guangzhou, China, ${ }^{2}$ Key Laboratory \\ of Tropical Disease Control, Ministry of Education, Sun Yat-sen University, Guangzhou, China, ${ }^{3}$ Provincial Engineering \\ Technology Research Center for Biological Vector Control, Guangzhou, China
}

The thymus is a vital organ of the immune system that plays an essential role in thymocyte development and maturation. Thymic atrophy occurs with age (physiological thymic atrophy) or as a result of viral, bacterial, parasitic or fungal infection (pathological thymic atrophy). Thymic atrophy directly results in loss of thymocytes and/or destruction of the thymic architecture, and indirectly leads to a decrease in naïve $T$ cells and limited $T$ cell receptor diversity. Thus, it is important to recognize the causes and mechanisms that induce thymic atrophy. In this review, we highlight current progress in infection-associated pathogenic thymic atrophy and discuss its possible mechanisms. In addition, we discuss whether extracellular vesicles/exosomes could be potential carriers of pathogenic substances to the thymus, and potential drugs for the treatment of thymic atrophy. Having acknowledged that most current research is limited to serological aspects, we look forward to the possibility of extending future work regarding the impact of neural modulation on thymic atrophy.

Keywords: thymus gland, atrophy, infections, immunosenescence, glucocorticoids

\section{INTRODUCTION}

Senility postponement is a topic of perennial importance for scientists. Aging inevitably leads to tissue damage and organ dysfunction, and individuals also become more sensitive to infections, tumors and other diseases as they age. Scientists have been studying mechanisms of human aging and searching for methods to postpone senility for many years, and several strong theories have been put forward, including the telomeric theory of aging and the free radical theory. Aging also impacts the immune system and thymic atrophy is the most obvious phenomenon of immune system degeneration.

The thymus is the main lymphoid organ of the human body. It is located anterior to the aortic arch and left brachiocephalic vein. It serves as the site for $\mathrm{T}$ cell maturation. The thymus parenchyma is surrounded by the thymic capsule, which extends into the parenchyma to form the lobular septum and separates the parenchyma into lobules. The thymus parenchyma consists of cortex and medulla, which are separated by the cortico-medullary junction (CMJ) (1). The cortex is constructed from thymic epithelial cells (TEC) as its framework and thymocytes filling in the interspace. The medulla is made of thymic epithelial cells, single positive (SP) thymocytes and macrophages. When common lymphoid progenitors originating from bone marrow migrate into the thymic cortex through vessels, they complete the expression of rearranged $\mathrm{T}$ cell receptors (TCR) in the outer cortex and change their phenotype from double negative (DN) thymocytes to double positive (DP) thymocytes; that is, from CD4-CD8- to CD4+CD8+ thymocytes. Positive selection and negative selection are two crucial processes for the continued development of DP 
thymocytes. Positive selection will clear DP thymocytes that cannot bind to MHC peptide, while negative selection will induce apoptosis in thymocytes that express self-reactive TCRs (2). After fulfilling the process of positive selection in the inner cortex and negative selection at the medulla, DP thymocytes become single positive thymocytes with self-tolerance; that is, CD4+CD8- or CD4-CD8+ thymocytes. SP thymocytes are then transported out of the thymus to $\mathrm{T}$ cell zones of the peripheral lymphoid tissues. In summary, the thymus performs these primary functions, which are essential for peripheral $\mathrm{T}$ cell renewal (1).

Thymic atrophy, also known as thymic involution, is inevitable upon aging, and is thus called age-associated thymic atrophy (3). In addition to human beings, thymic atrophy serves as an important characteristic aging hallmark for all species that possess a thymus. Nutrition is also involved: scientific findings indicate that zinc deficiency (4) and malnutrition (5) can cause thymic atrophy. Infection is also a vital factor. The thymus was previously thought to be an immune-privileged organ, but now it has been found that anti-pathogen responses can also be seen within thymus, causing thymic atrophy (6). Thus, infectious disease, as well as aging and nutrition, plays an important role in thymic atrophy. It is suggested that immune insufficiency is the end result of thymic atrophy (7). Thymic atrophy will lead to attenuation of immune reactions to pathogens and vaccines (3). The incident rate of tumors is positively correlated with age because of dysfunction of the monitoring of the immune system $(8,9)$. Typically, immunosurveillance should protect intact tissue against mutated cells that are recognized as foreign bodies (10). Besides the effects of aging, there are autoimmune diseases associated with thymic atrophy (11). Increased likelihood of pathogen-related mortality and death from opportunistic infection is also observed in patients with immune insufficiency (12). The thymus plays a crucial role in protection against COVID-19 in children $(13,14)$, whose thymus glands are more functional and active. Virus-specific plasma cells are accumulated in the perivascular space of the thymus (PST), located between thymic epithelial cells and blood circulation. According to the speculation of the researchers of this study (13), plasma cells, also named effector B cells, secrete IgG1 and IgG3 that are main protectors against viral infection. This may be one of the reasons that children are less susceptible to COVID-19. It is worth mentioning that there was no association between $\mathrm{T}$ cell development and susceptibility to COVID-19 observed in this study.

Age-associated thymic atrophy leads to decreased naive $\mathrm{T}$ lymphocytes, which is then followed by a series of immune sequelae mentioned above (10). This series of age-related changes that affect the immune system are defined as immunosenescence (15), whose main features are defective immune responses, increased systemic inflammation (16) and increased susceptibility to cancer (17). Age-associated thymic atrophy is characterized as expansion of the perivascular space, e.g. adipocytes and stroma. Meanwhile, the epithelial space of the thymus for thymopoiesis shrinks to less than $10 \%$ of thymic parenchyma by the age of 70 (10). Similarly, in infectious diseases, acute and chronic infection provokes alterations in inflammation and suppressive pathways that affect the function and integrity of many tissues. Depletion of thymocytes, particularly the cortical lymphocytes bearing the phenotype of double positive, is commonly observed (18). Different mechanisms have been proposed to explain age-associated thymic atrophy, including aging of the lymphocyte progenitor, defects in expression of the TCR gene and change in thymic microenvironment $(10,19,20)$. However, few scientific studies have focused on the mechanism of infection related to thymic atrophy.

Here, we review the mechanism and process of thymic atrophy driven by different pathogens, including viruses, bacteria, parasites and fungi, that have been reported in recent years, with a view to elucidating research on infection-related thymic atrophy. Tables 1-4 provide a summary of this work.

\section{VIRUSES}

Viruses can induce thymic atrophy through different mechanisms. In general, direct and indirect cell death induced by infection are two common means of thymic atrophy. The indirect cell death pathway includes cytokine alteration and glucocorticoid release. Here we present some typical examples, with further examples summarized in Table $\mathbf{1}$.

\section{Porcine Reproductive and Respiratory Syndrome Virus (PRRSV)}

Porcine reproductive and respiratory syndrome (PRRS) is characterized as reproductive failure and respiratory disorder in sows, as well as immune senescence (108). Porcine reproductive and respiratory syndrome virus (PRRSV) is the pathogen of PRRS, which can be divided into two types: PRRSV1 (formerly European type) and PRRSV-2 (formerly North American type) (21). PRRSV-1 has been further divided into four different subtypes according to sequence analysis (109) based on highly diverse ORF5 and ORF7 genetic sequences of PRRSV-1.

Highly pathogenic (HP) PRRSV strains have been identified in both PRRSV-1 and PRRSV-2 so far (110). Piglets infected in utero with the SD 23983 PRRSV strain demonstrated severe thymic atrophy, which leads to immunosuppression (111). HPPRRSV (HuN4 strain) has a much stronger tropism in the thymus than low pathogenic PRRSV (112). Researchers have demonstrated that HP-PRRSV (HuN4 strain) can lead to thymic atrophy, and can cause a significant loss of DP thymocytes when compared to low pathogenic PRRSV (CH-1a strain) (22). HPPRRSV attenuated strain shows a reduced ability to induce thymocyte atrophy (113), indicating that pathogenicity is positively correlated with the degree of thymic atrophy. Similarly, as for low virulent PR11 and high virulent PR40 PRRSV1 subtype 1 strains, thymic atrophy is more intense in the PR40 group (114). However, $\mathrm{CD}^{+} \mathrm{T}$ cells, the main apoptotic component, are not infected with HP-PRRSV, and viral nucleotides are only found in $\mathrm{CD}_{1} 4^{+}$monocyte/ 
TABLE 1 | Alterations and characteristics of virus-induced thymic atrophy.

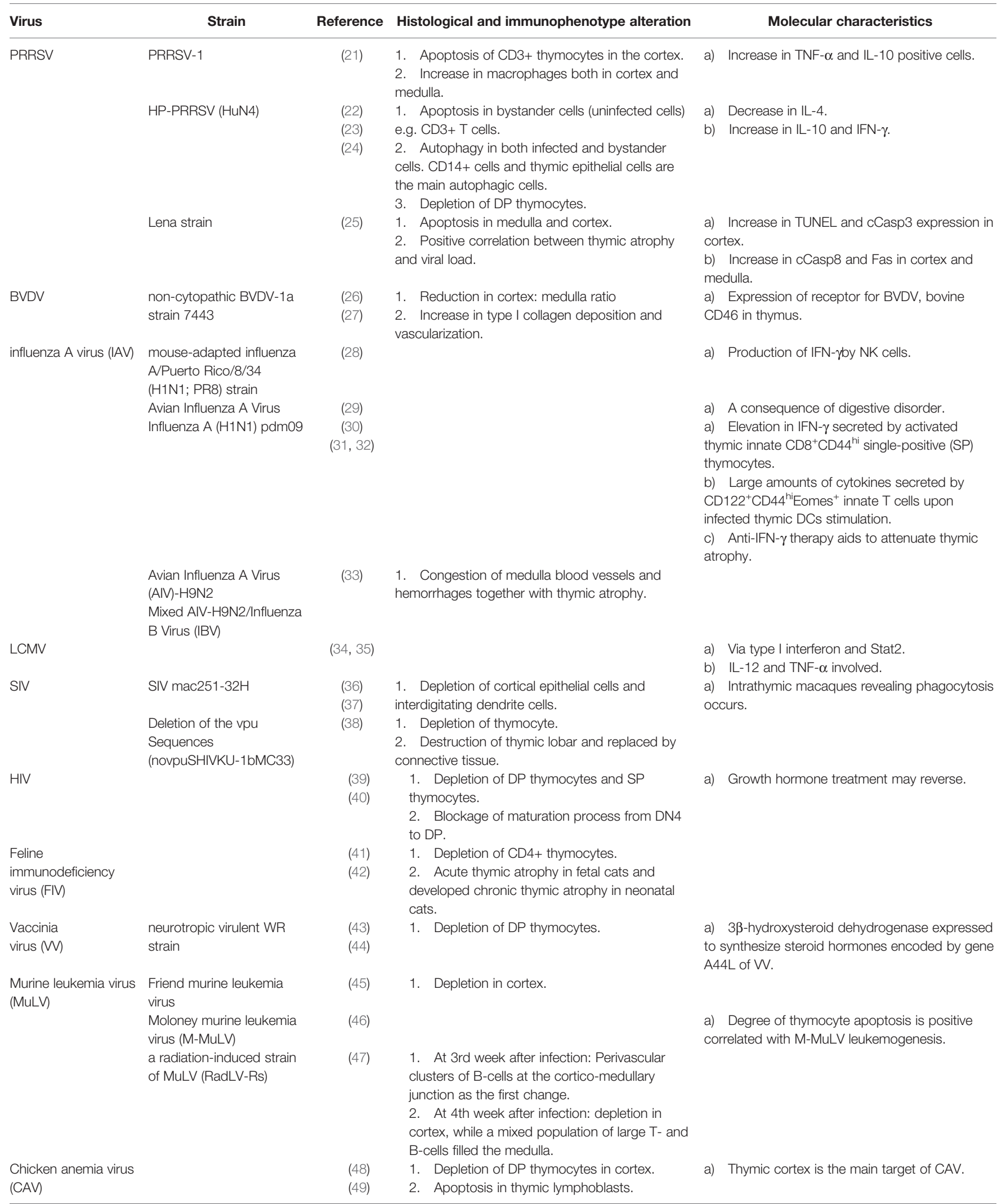


TABLE 1 | Continued

\begin{tabular}{|c|c|c|c|c|}
\hline Virus & Strain & Reference & Histological and immunophenotype alteration & Molecular characteristics \\
\hline $\begin{array}{l}\text { Duck enteritis virus } \\
\text { (DEV) }\end{array}$ & & $(50)$ & $\begin{array}{l}\text { 1. Depletion of thymic lymphocytes. } \\
\text { 2. Sustained immunosuppression as noted by } \\
\text { the secondary bacterial infection. }\end{array}$ & \\
\hline $\begin{array}{l}\text { Mouse hepatitis virus } \\
(\mathrm{MHV})\end{array}$ & $\begin{array}{l}\text { Mouse hepatitis virus A59 } \\
\text { (MHV-A59) }\end{array}$ & $(51)$ & 1. Apoptosis of DP thymocytes. & $\begin{array}{l}\text { a) Thymic epithelial cells have MHV receptors. } \\
\text { b) Infection of thymic epithelial cells led to } \\
\text { release of cytokines. }\end{array}$ \\
\hline CSFV & & $(52)$ & 1. Atrophy of thymus & $\begin{array}{l}\text { a) CSFV RNA was positive in the thymus when } \\
\text { postnatal persistent infection. }\end{array}$ \\
\hline MDPV & & (53) & 1. Atrophy of thymus. & \\
\hline $\begin{array}{l}\text { Newcastle disease } \\
\text { virus (NDV) }\end{array}$ & WNDV & $\begin{array}{l}(54) \\
(55)\end{array}$ & 1. Necrosis and depletion of the lymphocytes. & $\begin{array}{l}\text { a) Vitamin A dietary supplementation delayed } \\
\text { thymic atrophy. }\end{array}$ \\
\hline $\begin{array}{l}\text { Marek's disease } \\
\text { alphaherpesvirus } \\
\text { (MDV) }\end{array}$ & $\mathrm{RB}-1 \mathrm{~B}$ & $(56)$ & $\begin{array}{l}\text { 1. Cell death in both thymic cells replicating } \\
\text { MDV and uninfected cells in the thymus. } \\
\text { 2. Premature exit of DP thymocytes. }\end{array}$ & \\
\hline Rabies virus & & $(57,58)$ & 1. Depletion of DP thymocytes. & Reversed by adrenalectomy. \\
\hline $\begin{array}{l}\text { Reticuloendotheliosis } \\
\text { virus (REV) }\end{array}$ & & (59) & $\begin{array}{l}\text { 1. Decrease in thymus index } \\
\text { 2. Increase in thymic reticular endothelial cells, } \\
\text { inflammatory cell infiltration and nuclear } \\
\text { damage. }\end{array}$ & a) Increase the level of oxidative stress \\
\hline $\begin{array}{l}\text { Phocid herpesvirus } 1 \\
\text { (PhHV-1) }\end{array}$ & & $(60)$ & $\begin{array}{l}\text { 1. Thymic atrophy of grey seals Halichoerus } \\
\text { grypus }\end{array}$ & \\
\hline
\end{tabular}

PRRSV, porcine reproductive and respiratory syndrome virus; HP-PRRSV, highly pathogenic porcine reproductive and respiratory syndrome virus; BVDV, bovine viral diarrhea virus; LCMV, lymphocytic choriomeningitis virus; SIV, simian immunodeficiency virus; HIV, human immunodeficiency virus; CSFV, classical swine fever virus; MDPV, muscovy duck parvovirus; WNDV, velogenic viscerotropic pathotype of newcastle disease virus; DP, double positive.

macrophages (108), the main replicating sites of PRRSV in the thymus (21). This analysis suggests an indirect route to apoptosis induction, which may be correlated with cytokine release (108). Similar results in PRRSV-1 support the hypothesis above, especially in PRRSV-1 SUI-bel strain. Apoptosis of $\mathrm{CD}^{+}$ thymocytes in the cortex was noted and the number of TNF- $\alpha$ and IL-10 immuno-stained cells showed an increase in the infected group (21). There was also an increase in the number of macrophages in both the cortex and the medulla of the thymus (21). Cytokines released by macrophages may play an important role in thymocyte apoptosis.

Further research suggests that both apoptosis and autophagy occur in the thymus of piglets infected with HP-PRRSV (23). The main autophagic components are thymic epithelial cells, along with $\mathrm{CD} 14^{+}$cells (23). HP-PRRSV only induces apoptosis in bystander cells (uninfected cells), while autophagy occurs in both infected and bystander cells (23).

A recent hypothesis suggests that thymic antigen presenting cells (TAPCs) infected by PRRSV interact with DP thymocytes, which results in an acute deletion of DP thymocytes and a poor ability to recognize PRRSV and other pathogens (115).

\section{Influenza A Virus}

Influenza A virus (IAV) is one of the most common and important viruses that induces recurrent epidemics and causes high morbidity and mortality in the population. IAV infection can also induce thymic atrophy. Research involving mouseadapted influenza A demonstrated that NK-cells affect thymic atrophy via IFN- $\gamma$ production (28). The expression of proinflammatory cytokines is elevated in influenza A (H1N1) pdm09-infected thymus tissue (30), the most significant of which is IFN- $\gamma$ secreted by activated thymic innate $\mathrm{CD} 8^{+} \mathrm{CD} 44^{\text {hi }} \mathrm{SP}$ thymocytes (30). IAV can be presented by thymic DCs (30), resulting in rapid secretion of large amounts of cytokine by CD $122^{+} \mathrm{CD} 44^{\text {hi }}$ Eomes $^{+}$innate $\mathrm{T}$ cells $(31)$. This mechanism may also participate in IAV-induced thymic atrophy.

Avian IAV can lead to thymic atrophy and severe diarrhea in chicks, but thymic atrophy in such cases is thought to be the result of a digestive disorder (29).

\section{Immunodeficiency Virus}

Immunodeficiency virus is a retrovirus that affects a variety of animals in addition to humans (47). In human acquired immunodeficiency syndrome (AIDS), severe thymocyte depletion restricts $\mathrm{T}$ cell production in the thymus, which is the main pathogenesis of human immunodeficiency virus (HIV). Mice transgenic for HIV-1 Tat protein show an acute thymic atrophy, which is characterized by depletion of cortex and loss of the cortico-medullary border. DP thymocytes and SP thymocytes are significantly reduced as a result of the blocked maturation process from $4^{\text {th }}$ stage DN to DP (39).

In other animal models, Simian immunodeficiency virus (SIV)-induced thymic atrophy is characterized by severe depletion of cortical epithelial cells and interdigitating dendrite cells (36). SIV-induced thymic atrophy exhibits shrinkage of the thymic capsule, as opposed to age-related thymic atrophy that is characterized by an unaltered thymus capsule filled with adipose tissue (36). The Vpu protein of HIV-1 enhances the release of virion from infected cells. However, the Simian-Human Immunodeficiency Virus with the deletion of $\mathrm{Vpu}$ sequence (novpuSHIV $\mathrm{KU}_{\mathrm{K}-1 \mathrm{bMC} 33}$ ) can still result in severe thymic atrophy in macaques (38). In macaques infected with novpuSHIV $_{\mathrm{KU}-1 \mathrm{bMC} 33}$, depletion of thymocytes and destruction of thymic lobes was observed. Lobes were replaced by connective 
tissue (38), and further research is needed to fully understand the mechanism. HIV can be vertically transmitted to the subsequent generation through the parental pathway. In cats infected with feline immunodeficiency virus and serving as animal models for lentiviral immunodeficiency disease (41), fetal cats show acute thymic atrophy at birth with peak viremia while neonatal cats develop chronic thymic atrophy with low-level productive infection and viremia (42). Interestingly, thymic atrophy in fetal cats is rapid and transient, rebounding 46 days after infection (42). In humans, a reduction in thymus size has been observed in children who have been exposed to HIV but do not have qualitative immunodeficiency (116). Recent findings have showed that treatment of HIV-1 infected adults with growth hormone might reverse thymic atrophy (40).

\section{Other Viruses}

Many other domestic viruses are also reported to cause thymic atrophy. The thymus is one of the target organs of viruses. Apoptosis is induced by infection, and alteration in the thymic microenvironment also contributes to thymic atrophy.

Marek's disease is a lymphoproliferative disease of chickens, whose pathogen is Marek's disease alpha herpes virus (MDV) (117). Thymic cells infected with replicating MDV subsequently show significant apoptosis. MDV infection also promotes cell death of uninfected cells in the thymus. However, in cases of MDV infection, the number of T-cells in the blood is not significantly decreased, on the contrary, the lymphocytosis of $\mathrm{CD}^{+}$and $\mathrm{CD}^{+}{ }^{+} \mathrm{T}$ cells occurs (56). At present, thymic atrophy is a key indicator to evaluate a new Marek's disease vaccine (117-119).

Chicken anemia virus (CAV) can cause anemia in chickens, and thymic atrophy occurs in the CAV infected chicks (120). Depletion of lymphocytes in the thymus cortex is observed, which is characterized by a loss of $\mathrm{CD} 4^{+} \mathrm{CD} 8^{+} \mathrm{DP}$ thymocytes (48). CAV antigens, VP1 and VP3, are detected positively in thymic cortex, the main target of CAV (49). In cases of CAV infection, caspase 3 is detected mainly in cells that are compatible morphologically with thymic lymphoblasts (49) indicating that thymic apoptosis mainly occurs in lymphoblasts.

In mouse hepatitis virus (MHV) infection, the MHV receptor (MHVR) glycoprotein is detected on thymic epithelial cells but not on T lymphocytes. Infection of thymic epithelial cells leads to release of cytokines, which results in alteration of the microenvironment and apoptosis of immature $\mathrm{CD} 4^{+} \mathrm{CD} 8^{+} \mathrm{DP}$ lymphocytes (51).

In one study, calves were pre-infected with Bovine viral diarrhea virus (BVDV) and secondly infected with bovine herpesvirus 1 (BHV-1). BVDV pre-infected calves showed reduction in cortex: medulla ratio, with severe cortical thymic atrophy, increased type I collagen deposition and increased vascularization (26). The cellular receptor for BVDV, bovine CD46, can be purified from the thymus (27), which suggests that thymic cells may be directly infected by BVDV through the CD46 pathway.

Other mechanisms are also implicated in virus related thymic atrophy. Infection with Vaccinia virus (VV) induces severe thymic atrophy characterized by reduction of $\mathrm{CD} 4^{+} \mathrm{CD} 8^{+} \mathrm{DP}$ thymocytes in the thymus (43), and gene A44L of VV is reported to be responsible for encoding $3 \beta$-hydroxysteroid dehydrogenase which can synthesize steroid hormones. Thus, VV may affect thymic atrophy by regulating the production of steroid hormones itself (44). Lymphocytic choriomeningitis virus (LCMV) is reported to induce thymic atrophy via type I interferon and signal transducer and activator of transcription 2 (Stat2) (34). Induction of TNF together with high concentration of IL-12 seems to explain the immunotoxicities induced by LCMV infection (35). What's more, during LCMV infection, self-reactive $\mathrm{T}$ cells are able to leave the thymus and enter the peripheral circulation due to impaired negative selection (34). Classical swine fever virus (CSFV) in pigs (52), Muscovy duck parvovirus (MDPV) in ducks (53) and Newcastle disease virus (NDV) in cockerels (54) are all reported as causing thymic atrophy. However, the exact mechanism in each of these cases is still being studied.

In brief, PRRSV is a well-studied virus in the field of virus-related thymic atrophy. Its pathogenesis involves replication of virus in the thymus and changes in the thymus microenvironment and cytokines, which induces apoptosis or autophagy. While the mechanisms of thymic atrophy induced by other viruses have not yet been fully studied, some studies only confirmed that certain viruses may cause thymic atrophy, while others focused on the pathological changes of the thymus after infection. Additionally, some studies focused on changes in thymocyte subpopulations while others focused on changes in the thymus microenvironment. Thus, more comprehensive studies are needed to reveal the mechanisms by which other viruses induce thymic atrophy. Table 1 shows the specific characteristics of thymic atrophy caused by different viruses.

\section{BACTERIA}

Infections with bacterial pathogens are also known to result in thymic atrophy. Thymic atrophy induced by bacterial infection involves a variety of mechanisms, and the exact mechanism will depend on the type of bacteria that cause the infection. Therefore, it is crucial to determine the specific pathway and specific results of thymic atrophy caused by a given bacteria for the study and prevention of thymic atrophy induced by the bacteria.

\section{Salmonella Typhimurium}

The mechanism of thymic atrophy caused by Salmonella Typhimurium (S. Typhimurium) has been well studied. During $S$. Typhimurium infection in mice, there is a significant decrease in the number of DP thymocytes, but no obvious change in the number of SP thymocytes and peripheral lymphocytes (61). Majumdar et al. (62) further studied the changes in different subsets of thymocytes during S. Typhimurium infection, which revealed that subsets of DP1 $\left(\mathrm{CD} 5^{10} \mathrm{CD} 3^{\text {lo }}\right)$ and $\mathrm{DP} 2$ $\left(\mathrm{CD} 5{ }^{\text {hi }} \mathrm{CD} 3^{\text {int }}\right)$ were mainly reduced, while the surviving DP3 thymocytes $\left(\mathrm{CD} 5{ }^{\text {int }} \mathrm{CD} 3{ }^{\text {hi }}\right)$ expressed elevated amounts of intracellular Bcl2. Corresponding to that, SP thymocytes were more resistant to depletion but their maturation was delayed, 
leading to accumulation of $\mathrm{CD} 24^{\text {hi }} \mathrm{CD} 3{ }^{\text {hi }}$ SP thymocytes. A blockade in the developmental pathway of DN thymocytes was also observed and all the phenomena above were enhanced by IFN- $\gamma$. Indeed, S. Typhimurium indirectly leads to depletion of DP thymocytes by increasing endogenous glucocorticoid and IFN- $\gamma$. This induces apoptosis via various mechanisms involving mitochondrial membrane depolarization and activation of caspase-3, but not Fas/FasL pathway (61). Subsequent studies showed that the glucocorticoid and IFN- $\gamma$ mediated pathways led to the downstream activation of c-Jun $\mathrm{NH} 2$-terminal kinase (JNK) in DP thymocytes, which was crucial for apoptosis of immature thymocytes during infection. In turn, there are some feedback regulations of JNK that elevate the serum level of glucocorticoid and IFN- $\gamma$ (63). Other studies showed that lipopolysaccharides (LPS) could be the main pathogenic factor of thymic atrophy in chicks during infection with $S$. Typhimurium, and that the process might involve TLR4-FOS/ JUN signaling pathway (64). Interestingly, when attenuated strains were used to induce thymic atrophy, different results emerged. Ross et al. (65) found that thymic atrophy induced by attenuated strains of S. Typhimurium was neither dependent on regulation of endogenous glucocorticoids nor IFN- $\gamma$. Furthermore, the maturation and output of thymic $\mathrm{T}$ cells were maintained during atrophy. Once bacterial numbers decreased, thymocyte numbers recovered, indicating that the thymus has some adaptability to attenuated strains and can maintain its function during infection.

\section{Escherichia coli and Gastrointestinal Microbiota}

Thymus weight, cellularity, thymocyte viability and absolute number of DP thymocytes decrease after injection of Escherichia coli $(E$. coli) or $E$. coli-derived LPS into mice $(67,68)$. TNF- $\alpha$ and corticosterone play an important role in the apoptosis of thymocytes in vivo induced by LPS of E. coli (68). Other studies found that the LPS-induced thymic atrophy during $E$. coli infection was significantly mediated by leukemia inhibitory factor (LIF, a member of the IL- 6 cytokine family) which was able to enhance systemic and intrathymic corticosteroids (67). When cultured with $\mathrm{T}$ cells in vitro, high doses of the cholera toxin (CT) or its B subunits (CT-B) from E. coli induce apoptosis by increasing cAMP or by cross-linking of cell surface GM1 and CT-B $(121,122)$. Intravenous administration of CT or heat-labile enterotoxin (LT) induce decreased thymus weight due to in vivo necrosis of thymocytes, but not apoptosis $(69,70)$. However, intramuscular administration of LT to mice induces apoptosis in the thymus, which may be the result of the body's immune response, rather than the toxin directly interacting with thymocytes through circulation (71).

Thymic atrophy is observed in a model of sepsis induced by cecal ligation and puncture (CLP) in mice. Apoptotic thymocytes increase sphingosine-1-phosphate (S1P) in the thymus, which disrupts the normal S1P gradient in vivo, leading to thymic involution and inhibition of $\mathrm{T}$ cell emigration. S1P also increases IL-6 and aggravates the apoptosis of thymocytes (72). In another sepsis model induced by CLP or by continuous injection of $E$. coli-derived LPS, Kong et al. (73) observed some phenomena from the perspective of early $\mathrm{T}$ lineage progenitors (ETPs). In this model, there was a depletion of ETPs, which was due to decreased expression of some chemokine receptors such as CCR7, CCR9 and P-selectin glycoprotein ligand-1 on the surface of bone marrow (BM) progenitors for ETPs, contributing to impaired homing capacity of these cells. There was also a defect in lymphoid lineage commitment. Progenitors were more likely to differentiate towards the myeloid rather than the lymphoid lineage.

\section{Streptococcus}

Wang et al. (74) found that Streptococcus suis (S. suis) induced thymus apoptosis by promoting apoptosis of $\mathrm{CD}^{+}, \mathrm{CD}^{+} 4^{+}, \mathrm{DP}$ and thymic epithelial cells. By destroying mitochondrial function and releasing cytochrome $\mathrm{C}$ (CytC) and apoptosis-inducing factors (AIF) into the cytosol, S. suis triggers p53-dependent apoptosis. Caspase-dependent pathway is another way to induce thymocyte apoptosis during $S$. suis infection. The bioavailability of L-arginine is an important condition for thymogenesis (123). Studies have shown that L-arginine is an important regulator of the mTOR signaling pathway (124), which is essential for the development of T cells (125). Based on this theory, a Russian team found that Streptococcus pyogenes infection could induce thymic atrophy in mice and confirmed that this atrophy was inextricably associated with the reduction of L-arginine in the bloodstream by arginine deiminase produced by Streptococcus pyogenes (75). In fact, many pathogens that cause thymic atrophy can express products that reduce L-arginine in the blood (126).

\section{Staphylococcus}

Lin et al. (77) reported that staphylococcal enterotoxin B (SEB) could induce thymocyte apoptosis, and I-E molecule on antigenpresenting cells played an important role in this process. According to this report, in addition to a decrease in the number of DP thymocytes, there was a higher expression of surface markers such as CD25, TCR $\alpha \beta$, CD3, and CD69 in thymocytes after SEB injection, which was not observed in I-E negative mice. This report also mentions that staphylococcal enterotoxin A (SEA) can also induce thymocyte apoptosis independent of I-E expression.

\section{Mycobacterium}

In the study of mice infected with Mycobacterium avium ( $M$. avium), it was found that the synergistic effect of nitric oxide produced by IFN- $\gamma$-activated macrophages and glucocorticoid played a major role in inducing thymic atrophy (81). During $M$. avium infection, the number of thymocytes decrease, including earliest thymic precursors. This suggests defects in the homing of $\mathrm{BM}$ progenitor cells and their differentiation into thymocytes (81). In theory, Mycobacterium tuberculosis (M. tuberculosis) can also induce thymic atrophy. $M$. tuberculosis not only elevates levels of IFN- $\gamma$, IL- 6 and glucocorticoids, but also disrupts the endocrine system, increasing growth hormone, thyroid hormone, estradiol and prolactin (82). Abnormal elevations of these hormones may indicate impaired thymus function (127131). Injections of $M$. tuberculosis-derived cord factor (CF) and LPS instead of sulfides were proved to induce thymic atrophy 
(83). TNF- $\alpha$ and corticosterone increased remarkably after LPS injection, but they did not change significantly after CF injection. However, administration of anti-TNF- $\alpha$ antibody almost completely inhibited thymic atrophy caused by CF (83). Additionally, anti-TNF- $\alpha$ antibodies can also completely or partially inhibit thymocyte apoptosis caused by various gramnegative and gram-positive bacteria, such as E.coli, Klebsiella pneumoniae, Pseudomonas aeruginosa and Streptococcus pneumoniae (84). In this regard, the TNF- $\alpha$ signal pathway seems to be one of the common pathways leading to thymocyte apoptosis in various bacteria.

\section{Other Bacteria}

Merrick et al. (132) reported that after Listeria monocytogenes (LM) infection in mice, significant lymphocyte apoptosis was found in the $\mathrm{T}$ cell zones of the lymph nodes and spleen. Subsequently, Chen et al. (76) reported that P53, Bax and cmyc genes might co-regulate LM-induced thymocyte apoptosis. The relevant mechanisms need to be further studied.

Low dose aerosol infection with type A Francisella tularensis (F. tularensis) induces thymic atrophy in mice, where $F$. tularensis can be found in thymic tissue with large numbers of DP cells undergoing necrosis instead of apoptosis. This process is under the regulation of corticosteroids and TNF, rather than Fas (78). It has also been reported that, in the early stage, intraperitoneal injection of high-dose $F$. tularensis caused thymic atrophy through a series of stress responses, but no bacteria were found in the thymic tissue (133).

Intraperitoneal administration of culture supernates from Yersinia enterocolitica ( $Y$. enterocolitica) causes thymocyte apoptosis and increases the proportion of TCR $\alpha \beta^{\text {high }}$ cells in mice, which is related to the increase in the percentage of cells with high levels of V $\beta 6$ and V 88 TCRs (79). In addition, LPS is not involved in thymic atrophy induced by Y. enterocolitica (79). The V antigen of Yersinia pestis can interact with receptor-bound human IFN- $\gamma$ located in thymocytes, triggering thymocyte apoptosis in vitro (80). Again, the specific mechanism here remains to be clarified.

In general, studies on bacteria-induced thymic atrophy are relatively complete, and some of them even delve into the level of signaling pathways and gene expression. Considering that different bacteria have different invasiveness and produce different toxins, the mechanisms of thymic atrophy induced by different bacteria cannot be simply classified. In other words, the mechanisms by which one type of bacteria induces thymic atrophy are often different from the mechanisms utilized by other bacteria. Therefore, it is important to explore the specific mechanisms of thymic atrophy caused by each type of bacteria, which puts forward new requirements for the future research of thymic atrophy. Table 2 shows the specific characteristics of thymic atrophy caused by different bacteria.

\section{PARASITES}

Parasite-induced thymic atrophy is associated with Trypanosoma cruzi, Leishmania infantum, Plasmodium, Angiostrongylus cantonensis, and Schistosoma. This kind of thymic atrophy is related to apoptosis of thymocytes (especially DP thymocytes), reduced proliferation of thymocytes, premature exiting of thymocytes and alteration of the thymic microenvironment, which may be the direct effect of parasites. Parasites can interrupt hormone balance to induce thymic atrophy indirectly. More detailed mechanisms of some parasite-induced thymic atrophy are yet to be determined.

\section{Trypanosoma cruzi}

The hemoflagellate protozoan T. cruzi causes Chagas disease, a potentially life-threatening disease with complications such as cardiomegaly, gastrointestinal disease, and peripheral neuropathy in some cases (134). T. cruzi is transmitted by the vector of blood-sucking insects of the subfamily Triatominae and usually found in South America, Mexico, the United States, Europe and the Western Pacific region $(135,136)$. It attacks human organs like the thymus, spleen and lymph nodes.

Several studies have revealed thymic atrophy during T. cruzi infection. Once infected by $T$. cruzi, a distinct thymic atrophy occurred with loss of cortical thymocytes, apoptosis of thymocytes (especially DP thymocytes) (137), migration disturbances, premature exiting of thymocytes, decreased IL-2 level and increased IL-4,5,6, IFN- $\gamma$, TNF- $\alpha$ level (85-87). The mechanism underlying premature release of DP thymocytes is being studied. Initially it was believed that it was related to negative selection, but recent research has confirmed that the negative selection is normal during experimental T. cruzi infection (138). Experiments revealed that the key intrathymic factors essential for promoting negative selection of thymocytes, such as the expression of autoimmune regulator factor (AIRE) gene, tissue-restricted antigen (TRA) gene and proapoptotic Bim protein, remain normal during acute Chagasic thymic atrophy (138). Subsequent experiments further confirmed this by injecting ovalbumin (OVA) peptide into OVA-specific TCR transgenic mice with or without infection-induced thymic atrophy, in which infection promoted apoptosis of OVAspecific thymocytes (138). Except for DP thymocytes, researchers found an increase in peripheral CD4-CD8- (DN) thymocytes in patients with severe cardiomyopathy of Chagas disease. In the thymus of T. cruzi infected mice, researchers detected decreased transcription of S1P kinase 1 and 2 genes associated with S1P biosynthesis and increased transcription of the S1P lyase gene associated with S1P inactivation, indicating decreased intrathymic levels of S1P. However, DN thymocytes upregulate $\mathrm{S} 1 \mathrm{P}$ receptor during infection, resulting in $\mathrm{DN}$ thymocytes migrating to peripheral blood where the level of S1P is relatively higher $(139,140)$. The trans-sialidase of T. cruzi can activate the MAPK-JNK pathway and actin filament mobilization in thymocytes, modulating the adhesion of thymocytes to TECs and their migration towards extracellular matrix, or modulating the escape of immature thymocytes during infection (141). Abnormal migration and export of thymocytes are not only related to the cell itself, but also to the surrounding microenvironment. Scientists found that the TECs infected by T. cruzi exhibited an increased expression of extracellular matrix (ECM), especially the fibronectin (FN), which led to deposits of ECM and enhancement of TECs-infection and 
TABLE 2 | Alterations and characteristics of bacteria-induced thymic atrophy.

\begin{tabular}{|c|c|c|c|}
\hline Bacteria & Reference & Histological and immunophenotype alteration & Molecular characteristic \\
\hline $\begin{array}{l}\text { Salmonella } \\
\text { Typhimurium }\end{array}$ & $\begin{array}{l}(61) \\
(62) \\
(63) \\
(64) \\
(65) \\
(66)\end{array}$ & $\begin{array}{l}\text { 1. Depletion of DN and DP thymocytes. DP1 and DP2 decreased significantly } \\
\text { while the expression of } \mathrm{Bcl} 2 \text { in DP3 increased. } \\
\text { 2. Delayed maturation of SP led to the accumulation of } \mathrm{CD} 24^{\text {high }} \mathrm{CD} 3^{\text {high }} \mathrm{SP} \\
\text { cells. } \\
\text { 3. Blockage of the development of DN1. } \\
\text { 4. Apoptosis in thymic cortex in chicks, but no significant change in } \mathrm{CD}^{+} / \\
\mathrm{CD} 8^{+} \mathrm{T} \text { cell ratio. } \\
\text { 5. Thymic atrophy but maintained T cell maturation and migration in } \\
\text { attenuated strains (SL3261) infection. Increase in naive T cells in peripheral } \\
\text { lymphatic organs. }\end{array}$ & $\begin{array}{l}\text { a) Elevation of glucocorticoid, IFN- } \gamma \text { and TNF- } \alpha \text {. } \\
\text { b) Elevation of pJNK in DP. } \\
\text { c) Increase in IL-22, IL8L2, and CCL4 in chicks. } \\
\text { d) Aggravation of thymic atrophy in mice lacking in } \\
\text { receptor guanylyl cyclase C. }\end{array}$ \\
\hline Escherichia coli & $\begin{array}{l}(67,68) \\
(69,70) \\
(71)\end{array}$ & $\begin{array}{l}\text { 1. Decrease in thymus weight, cellularity, thymocyte viability. } \\
\text { 2. Depletion of DP thymocytes. } \\
\text { 3. Necrosis of thymocytes when administrated with } C T \text { or LT. } \\
\text { 4. Apoptosis of thymocytes but increase in } C D 3^{+} T \text { cells when administrated } \\
\text { intramuscularly. }\end{array}$ & Increase in TNF- $\alpha$, corticosteroid and LIF. \\
\hline $\begin{array}{l}\text { Intestinal } \\
\text { bacteria }\end{array}$ & $\begin{array}{l}(72) \\
(73)\end{array}$ & $\begin{array}{l}\text { 1. Depletion of DP and SP thymocytes. } \\
\text { 2. Inhibition of T cell egress. } \\
\text { 3. Impaired migration of BM progenitors to thymus caused a decrease in } \\
\text { ETPS. }\end{array}$ & $\begin{array}{l}\text { a) Elevation in intrathymic S1P level. } \\
\text { b) Decrease in serum S1P level. } \\
\text { c) Elevation in serum IL-6 and glucocorticoids. }\end{array}$ \\
\hline $\begin{array}{l}\text { Streptococcus } \\
\text { suis } \\
\text { Streptococcus } \\
\text { pyogenes }\end{array}$ & $\begin{array}{l}(74) \\
(75)\end{array}$ & $\begin{array}{l}\text { a) Apoptosis of } \mathrm{CD}^{+}, \mathrm{CD} 14^{+} \mathrm{T} \text { cells, DP thymocytes and epithelial cells. } \\
\text { b) Increase in SP cells in thymus while decrease in blood. } \\
\text { 1. Depletion of DP thymocytes. } \\
\text { 2. Increase in the proportion of DN and SP thymocytes. } \\
\text { 3. Increase in Helios }{ }^{+} \text {Foxp3 } 3^{+} \text {Treg cells and Foxp3 }{ }^{+} \mathrm{CD} 25^{+} \text {Treg cells. }\end{array}$ & $\begin{array}{l}\text { a) Disorder of cytokine, including IL-2, IL-6, IL-12, } \\
\text { TNF and IL-10. }\end{array}$ \\
\hline $\begin{array}{l}\text { Listeria } \\
\text { monocytogenes }\end{array}$ & $(76)$ & 1. Apoptosis of thymocytes. & $\begin{array}{l}\text { a) Increased expression of p53, Bax and c-myc } \\
\text { genes. }\end{array}$ \\
\hline Staphylococcus & $(77)$ & $\begin{array}{l}\text { 1. Depletion of DP thymocytes. } \\
\text { 2. Increase in expression of CD25, TCR } \alpha \beta, C D 3 \text { and CD69. }\end{array}$ & \\
\hline $\begin{array}{l}\text { Francisella } \\
\text { tularensis }\end{array}$ & $(78)$ & 1. Necrosis of DP cells in cortex. & a) Increasing TNF- $\alpha$ and cortisol in serum. \\
\hline $\begin{array}{l}\text { Yersinia } \\
\text { enterocolitica } \\
\text { Yersinia pestis }\end{array}$ & $\begin{array}{l}(79) \\
(80)\end{array}$ & $\begin{array}{l}\text { 1. Depletion of DP thymocytes. } \\
\text { 2. Increase in TCR } \alpha \beta^{\text {high }} \text { cells, especially in } V \beta 6^{\text {high }} \text { and } V \beta 8^{\text {high }} \text { cells. } \\
\text { Apoptosis of thymocytes and Jurkat T-cells. }\end{array}$ & \\
\hline $\begin{array}{l}\text { Mycobacterium } \\
\text { avium }\end{array}$ & (81) & $\begin{array}{l}\text { 1. Depletion of all cell types, especially DP cells. } \\
\text { 2. Impaired migration of BM progenitors to thymus. }\end{array}$ & $\begin{array}{l}\text { a) Increase in production of nitric oxide from } \\
\text { macrophages. } \\
\text { b) A slight increase in corticosterone and increased } \\
\text { sensitivity of thymocytes to glucocorticoid-induced } \\
\text { apoptosis. }\end{array}$ \\
\hline $\begin{array}{l}\text { Mycobacterium } \\
\text { tuberculosis }\end{array}$ & $\begin{array}{l}(82) \\
(83)\end{array}$ & 1. Apoptosis in cortex and disappearance of CMJ and cortex. & $\begin{array}{l}\text { a) Elevation of glucocorticoid and TNF- } \alpha \text {. } \\
\text { b) Increased levels of various cytokines together with } \\
\text { disorders of the endocrine system. }\end{array}$ \\
\hline $\begin{array}{l}\text { Klebsiella } \\
\text { pneumoniae } \\
\text { Pseudomonas } \\
\text { aeruginosa } \\
\text { Streptococcus } \\
\text { pneumoniae }\end{array}$ & (84) & $\begin{array}{l}\text { 1. Disappearance of CMJ. } \\
\text { 2. Depletion of DN, DP, SP thymocytes, especially DP cells. }\end{array}$ & a) Elevation of TNF- $\alpha$ \\
\hline
\end{tabular}

$D N$, double negative; $D P$, double positive; $C T$, cholera toxin; $L T$, heat-labile enterotoxin; LIF, leukemia inhibitory factor; SP, single positive; CMJ, cortico-medullary junction.

thymocyte-TECs interaction. This may be related to the abnormal migration and export of abnormal thymocytes (142). Pe'rez et al. (85) unraveled that TNF- $\alpha$ together with FN triggered alterations in thymocyte migration and promoted the export of premature thymocytes, which linked the increased TNF- $\alpha$ (induced by T. cruzi infection) and fibronectin deposits with abnormal migration and export of thymocytes. Galectin-3, produced mainly by TECs, is also found to accelerate the premature death of thymocytes (143).

In addition to SP thymocytes, the thymus is also the site of differentiation of natural Tregs. T. cruzi infection gives rise to a noticeable loss of Tregs and results in localization, phenotypic, and functional abnormalities of the remaining Tregs (144). In addition, the differentiation of CD4+Foxp3 $+\mathrm{T}$ cells in peripheral blood is impaired due to an abnormal Th1-like phenotype and functional changes caused by $T$. cruzi infection, which may aggravate the immune imbalance and further affect the progression of the disease $(144,145)$.

Researchers further found that $T$. cruzi infection could induce thymic atrophy through affecting hormones. During infection, cytokines such as IL-1, IL-6, and TNF- $\alpha$ are obviously elevated, which stimulates the hypothalamic-pituitary-adrenal (HPA) axis and then increases the production of glucocorticoid, which is the main course of thymic atrophy $(87,146)$. For instance, elevation of 
IL-6 is found to be involved in the disruption of the differentiation of DN (88). Increased glucocorticoid can contribute to DP thymocyte apoptosis via caspase-8 and caspase-9 (147) and mediate premature release of DP thymocytes to the periphery, which may lead to autoimmune responses such as myocarditis (148). These effects can be reversed largely by blocking glucocorticoid receptors through steroid receptor antagonist RU486, resulting in an increase in thymus weight and the proportion and number of DP thymocytes. However, these effects cannot be reversed in TNF receptor 1 and 2 knockout mice (87, 147, 149). Eduardo Roggero et al. (150) considered that endogenous glucocorticoid was protective for the host during infection, given the fact that blockade of glucocorticoid receptor by RU486 resulted in elevated TNF- $\alpha$ level and accelerated death in experimental mice.

As noted, glucocorticoids induce apoptosis of thymocytes. In contrast, prolactin, another stress-induced hormone, antagonizes the apoptosis mediated by glucocorticoid (151-153). Glucocorticoid and prolactin have a mutual influence on thymic atrophy during $T$. cruzi infection. Researchers confirm that systematic prolactin impairment during infection increases the level of glucocorticoid, leading to thymic atrophy. Injection of metoclopramide (MET) enhances prolactin secretion, limiting the glucocorticoid-induced thymic atrophy and the export of immature DP thymocytes to the periphery (154).

Sex steroids also play a significant role in thymic atrophy during T. cruzi infection. Testosterone is an immunosuppressor, while dehydroepiandrosterone (DHEA) is an immunopotentiator that counteracts immunosuppressive effects of glucocorticoid $(155,156)$. Testosterone promotes the synthesis and release of thymogenic glucocorticoids by upregulating enzymes involved in glucocorticoid synthesis, leading to anti-proliferative and apoptotic responses of thymocytes (157). Another study showed that testosterone was involved in the apoptosis of thymocytes induced by exogenous changes of the surface sialylation, which is catalyzed by transsialidase (virulence factor of T. cruzi) in vivo, where the alternated sialyl residue interacts with TECs. This apoptosis process involves caspase-3 (158). Treatment with DHEA has been reported to enhance thymocyte proliferation and reduce TNF- $\alpha$ production during the acute phase of infection (159). Interestingly, in another study, DHEA treatment induced thymic atrophy via classical estrogen signaling pathways (160). To date, the mechanism of action of DHEA is unclear and more research is needed to elucidate its role.

To better understand the mechanism of thymic atrophy caused by $T$. cruzi infection, researchers tried to understand it by using molecular patterns. They found that 29 microRNAs in infected TEC were expressed differently in genes related to cell death, chemotaxis and adhesion. This highlighted that microRNAs may be mediators of thymic atrophy during $T$. cruzi infection (161). For example, the elevated level of miR10a in TEC, which participates in $\mathrm{T}$ cell differentiation in the thymus through TGF- $\beta$ stimulation, may influence thymic atrophy during infection $(161,162)$.

\section{Leishmania infantum}

Leishmania infection causes leishmaniasis, which is transmitted via female phlebotomine sandflies. Zoonotic leishmaniasis shows different clinical forms such as visceral leishmaniasis, cutaneous leishmaniasis, or muco-cutaneous leishmaniasis (163). L. infantum is the main zoonotic pathogen that infects humans, usually in the form of visceral leshmaniasis (163).

Thymic atrophy is also observed in L. infantum infected malnourished mice. As a precondition, malnutrition has a deleterious effect on the $\mathrm{T}$ cell-mediated immune response to Leishmania infantum infection. L. infantum infection combined with protein malnutrition leads to decreased chemotactic factors, dysregulation of migratory factors, decreased cortical area, decreased proliferation and increased apoptosis. Altered protein abundance suggests that a dysfunctional thymic microenvironment contributes to thymic atrophy $(89,90)$.

\section{Plasmodium}

Plasmodium is the cause of malaria and is transmitted through the bite of anopheles mosquitoes (164). Malaria has symptoms like fever, chills, headache, body-aches, cough, diarrhea and, in severe cases, brain, lung or kidney damage (165). Plasmodium berghei and Plasmodium chabaudi are rodent malaria parasites, widely used in mice models of malaria infection (166).

$P$. berghei is often observed in the thymus of infected experimental mice (91). P. berghei infection results in pronounced loss of thymus weight, loss of cortical-medullary delimitation, apoptosis and premature egress of thymocytes, especially DP and DN thymocytes $(91,92)$. Based on the degree of apoptosis, the apoptosis pattern can be divided into three types: starry-sky pattern of diffuse apoptosis maintaining cortical-medullary structure, intense apoptosis with cortical atrophy and severe cortical thymocyte depletion resulting in cortical-medullary inversion (167). During $P$. berghei infection, thymic atrophy is accompanied by changes in the microenvironment, where CXCL12 and CXCR4 are significantly increased, CCL25 and CCR9 are significantly decreased, the expression of the ECM component is increased, and the expression of laminin and $\mathrm{FN}$ receptor on thymocyte surfaces are downregulated, thereby altering the migration pattern of thymocytes (93).

Similarly, Plasmodium chabaudi causes thymic atrophy, and the number of mature, SP (CD4+ or CD8+) and $\delta \gamma+\mathrm{T}$ cells in the thymus decreases (94). Recently, the effect of Plasmodium yoelii lethal (17XL) and Plasmodium yoelii nonlethal (17XNL) on the thymus has been illuminated. During $P$. yoelii lethal (17XL) infection, the decrease of DP and CD4+ SP thymocytes, the reduced proliferation of DP thymocytes and the downregulation of CD8 expression on the thymic T-cell subpopulations were observed. However, during $P$. yoelii nonlethal (17XNL) infection, an earlier decrease of DN, DP, and CD4+ SP thymocytes and the reduced proliferation of DN and DP thymocytes were observed. This effect is reversible, but it is even greater when parasitemia is much lower. In addition, in Plasmodium infection, TNF- $\alpha$ has a protective effect on the thymus, while the increase of TNF- $\alpha$ during T. cruzi infection exacerbates thymic atrophy (95). Interestingly, the co-infection of malaria and cutaneous leishmaniasis may influence the outcome of thymic atrophy. Researchers found that thymus glands co-infected with Leishmania braziliensis and $P$. yoelii recovered earlier from atrophy than those infected with P. yoelii alone (168). 


\section{Angiostrongylus cantonensis}

Angiostrongylus cantonensis, a rat lungworm, causes human angiostronglyliasis. Humans, its non-permissive hosts, are infected by ingesting undercooked snails or slugs, paratenic hosts such as prawns, or infected larvae-contaminated vegetables (169). It usually induces eosinophilic meningitis in humans (170). Recent research found that it could also cause thymic atrophy in the non-permissive host, which may be explained by two mechanisms. One is the activation of the HPA axis, which impairs thymocyte development (96). Another is the direct action of soluble antigen from $A$. cantonensis, which leads to increased apoptosis of thymic stromal cells and thymocytes (97).

\section{Schistosoma}

Schistosoma is mainly prevalent in endemic regions of Africa and is also seen in the Middle East, Caribbean, South America, and South East Asia (171). The most common pathogenic species include Schistosoma haematobium, Schistosoma mansoni and Schistosoma japonicum, which cause urinary, intestinal and hepatosplenic schistosomiasis respectively $(172,173)$. Most infected people show no, or limited, atypical symptoms such as abdominal pain, diarrhea, anorexia, ascites, splenomegaly and portal hypertension (173).

The thymic cortex atrophied and the number of cortical thymocytes decreased in mice infected with S. mansoni, resulting in the loss of distinction in the corticomedullary region during the acute infection phase (98). S. japonicum can also induce thymic atrophy with the accumulation of both CD8 +CD28- T cells and CD4+CD28- T cells (99). In addition, thymocytotoxic autoantibodies induced by $S$. japonicum were found in the thymus (100).

In summary, $T$. Cruzi is currently the most thoroughly studied parasite that causes thymic atrophy. The mechanisms of T. Cruzi -induced thymic atrophy mainly include apoptosis of thymocytes, premature exiting of thymocytes, alteration of the thymic microenvironment and regulation of hormones. So far, there are few studies on thymic atrophy caused by other parasites, and most of them focused on changes in thymus structure and changes in different thymocyte subpopulations, including cortical loss, CMJ loss and depletion of certain T cell subgroups (more details could be seen in Table 3). It needs further exploration in molecular mechanisms, changes of the thymic microenvironment and the interaction between the host and parasites. Besides, given that parasites are typical pathogens of chronic infection, more mechanisms of thymic atrophy induced by parasites need to be further studied, which is of great significance to study the damage of chronic infection to the body.

\section{FUNGUS}

Paracoccidioides brasiliensis ( $P$. brasiliensis, $P b$ ) can invade the thymus causing severe thymic atrophy. Brito et al. (101) reported that after intraperitoneal injection of $P$. brasiliensis, the weight of the thymus decreased, the thymic cortex degenerated substantially and the CMJ disappeared. In the medullary region, $P b$ yeast cells were surrounded by histiocytes and there was predominant inflammatory infiltration of neutrophils and eosinophils in the medullary and subcapsular region. A subsequent study by Di Gangi et al. (102) showed that the spatial distribution of TECs was misplaced after $\mathrm{Pb}$ invasion of the thymus. The gene expression levels of IL-2, IL-7, IL-17, TNF$\alpha$ and autoimmune regulator (AIRE) in the thymus increased significantly. $P b$-induced thymic atrophy did not change the proportion of the various thymocyte subpopulations, that is, the cell number of all subpopulations decreased in the same proportion. This is different from the thymic atrophy characterized by significant reduction of DP cells caused by other pathogens. The increased expression of CCL19 and CCR7 in the thymus of infected mice indicated that the maturation of thymocytes was accelerated and the migration ability of thymocytes was stronger than that of the control group. In addition, autoreactive $\mathrm{T}$ cells that should have been eliminated during negative selection were found in peripheral lymphoid tissue, suggesting a potential risk of autoimmune disease after $\mathrm{Pb}$ infection. Costa et al. (103) established a model of chronic infection of $\mathrm{Pb}$ in mice. In the process of chronic infection, $\mathrm{Pb}$ severely infiltrated the thymus gland and granulomas were formed. In addition to the increased levels of IL-1 $\beta$, IL-17, IL18 , IFN- $\gamma$ and TNF- $\alpha$ in the thymus, high expression of caspase1 and caspase- 8 and the activation of inflammasome NLRP3 were also detected. Furthermore, an increase in the proportion of Th17 and $\mathrm{CD}^{+}$IFN- $\gamma$ producing $\mathrm{T}$ cells in the thymus was detected, suggesting that mature $\mathrm{T}$ cells returned to the thymus to participate in the inflammatory response. Finally, apoptosis of thymocytes and thymic epithelial cells occurred, and the morphology and function of the thymus changed, forming the characteristics resembling secondary lymphoid tissues.

Some fungi release substances that mediate thymic atrophy. Gliotoxin produced by Aspergillus fumigatus has been proved to induce apoptosis of thymocytes in vivo (104). The T-2 toxin produced by the Fusarium species could also induce apoptosis of four thymocyte subsets (DN, DP, $\left.\mathrm{CD} 8^{+} \mathrm{CD} 4^{-}, \mathrm{CD} 8^{-} \mathrm{CD} 4^{+}\right)$in vivo, resulting in thymic atrophy, but this process did not involve regulation of glucocorticoid and TNF- $\alpha$ (105). In addition, there has been a report of thymic atrophy in fish caused by Saprolegnia (106). More information about fungi that induce thymic atrophy can be seen in Table 4 .

\section{DISCUSSION}

Thymic atrophy induced by pathogens is a common phenomenon in infectious diseases. At the structural level, thymic atrophy caused by different pathogens presents certain similarities, but also has differences. In terms of structural alteration, the thymic cortex seems to be mainly affected by thymic atrophy. Depletion of thymocytes in the cortex can be observed in PRRSV, BVDV, SIV, MuLV, Salmonella Typhimurium, Francisella tularensis and many other pathogens. Accompanied by cortical involvement, CMJ also 
TABLE 3 | Alterations and characteristics of parasite-induced thymic atrophy.

\begin{tabular}{|c|c|c|c|}
\hline Parasite & Reference & Histological and immunophenotype alteration & Molecular characteristic \\
\hline Trypanosoma cruzi & $\begin{array}{l}(85,86) \\
(87,88)\end{array}$ & $\begin{array}{l}\text { 1. Cortical thymocytes loss. } \\
\text { 2. Apoptosis of thymocytes, especially DP } \\
\text { thymocytes. } \\
\text { 3. Migration disturbances. } \\
\text { 4. Premature exit of thymocytes. }\end{array}$ & $\begin{array}{l}\text { a) Decrease in IL-2. } \\
\text { b) Increase in IL-4,5,6, IFN- } \gamma \text {, TNF- } \alpha \text {. }\end{array}$ \\
\hline Leishmania infantum & $(89,90)$ & $\begin{array}{l}\text { 1. Reduced cortical area. } \\
\text { 2. Decreased proliferation and increased apoptosis. }\end{array}$ & a) Reduced chemotactic factors and dysregulated of migratory factors. \\
\hline Plasmodium berghei & $(91-93)$ & $\begin{array}{l}\text { 1. Loss of cortical-medullary delimitation. } \\
\text { 2. Apoptosis of thymocytes especially DP and DN } \\
\text { thymocytes. } \\
\text { 3. Premature exit of thymocytes. }\end{array}$ & $\begin{array}{l}\text { a) Altered thymic microenvironment with significantly increased CXCL12 } \\
\text { and CXCR4, decreased CCL } 25 \text { and CCR9. } \\
\text { b) Increased expression of ECM component, downregulated expression } \\
\text { of laminin and FN receptor on thymocytes surface. }\end{array}$ \\
\hline $\begin{array}{l}\text { Plasmodium } \\
\text { chabaudi }\end{array}$ & $(94)$ & 1. Depletion of SP (CD4+ or CD8+) and $\delta \gamma+\mathrm{T}$ cells. & \\
\hline $\begin{array}{l}\text { Plasmodium yoelii } \\
\text { lethal (17XL) }\end{array}$ & $(95)$ & $\begin{array}{l}\text { 1. Depletion of DP and CD4+ SP thymocytes. } \\
\text { 2. Reduced proliferation of DP thymocytes. } \\
\text { 3. Downregulation of CD8 expression. }\end{array}$ & \\
\hline $\begin{array}{l}\text { Plasmodium yoelii } \\
\text { nonlethal (17XNL) } \\
\text { Angiostrongylus } \\
\text { cantonensis }\end{array}$ & $\begin{array}{c}(95) \\
(96,97)\end{array}$ & $\begin{array}{l}\text { 1. Depletion of DN, DP, and CD4+ SP thymocytes. } \\
\text { 2. Reduced proliferation of DN and DP thymocytes. } \\
\text { 1. Depletion of CD3+, CD4+, and CD8+ T cells. } \\
\text { 2. Increased thymocytes and thymic epithelial cells } \\
\text { apoptosis. }\end{array}$ & \\
\hline $\begin{array}{l}\text { Schistosoma } \\
\text { mansoni }\end{array}$ & $(98)$ & $\begin{array}{l}\text { 1. Cortical thymocytes loss. } \\
\text { 2. Loss of distinction in the corticomedullary region. }\end{array}$ & \\
\hline $\begin{array}{l}\text { Schistosoma } \\
\text { japonicum }\end{array}$ & $(99,100)$ & $\begin{array}{l}\text { 1. Thymic atrophy but with both CD8+CD28- T cells } \\
\text { and CD4+CD28- T cells increased. }\end{array}$ & Thymocytotoxic autoantibodies was found in thymus. \\
\hline
\end{tabular}

$D P$, double positive; ECM, extra-cellular matrix; $S P$, single positive; $D N$, double negative.

becomes obscure. Additionally, there are other histological changes that can be observed, including collagen deposition in BVDV (26) and congestion in (AIV)-H9N2 (33).

The thymus is the specific site for $\mathrm{T}$ cell maturation, and therefore, thymic atrophy will lead to a series of dysfunctions in the thymocyte maturation process. Positive selection occurs in the inner cortex whereas negative selection occurs in the medulla. The cortex and (occasionally) the medulla are structurally damaged in infection-induced thymic atrophy, thus interrupting both positive and negative selection. Failing to undergo positive selection, a premature exit of DP thymocytes is observed in MDV (56), Trypanosoma cruzi $(85,86)$ and
Plasmodium berghei $(91,92)$. Disordered cortical structure leads to delayed maturation of SP thymocytes, which results in the accumulation of $\mathrm{CD} 24^{\text {high }} \mathrm{CD} 3{ }^{\text {high }} \mathrm{SP}$ cells. This phenomenon is observed in Salmonella Typhimurium infection (62). Skipping the process of negative selection, $\mathrm{T}$ cells become auto-reactive. T. cruzi infection-induced myocarditis may be associated with it (148). Such auto-immune diseases have also been reported in P. brasiliensis infection (102). As for the functional alteration of infection-induced thymic atrophy, double positive (DP) thymocytes are the general cluster of depletion. A recent study shows that auto-immunity facilitates the death of thymic epithelial cells through returning Th1 cells

TABLE 4 | Alterations and characteristics of fungus-induced thymic atrophy.

\begin{tabular}{|c|c|c|c|}
\hline Fungus & Reference & $\begin{array}{l}\text { Histological and immunophenotype } \\
\text { alteration }\end{array}$ & Molecular characteristic \\
\hline $\begin{array}{l}\text { Paracoccidioides } \\
\text { brasiliensis }\end{array}$ & $\begin{array}{l}(101)(102) \\
(103)\end{array}$ & $\begin{array}{l}\text { 1. Structural disorganization and intense } \\
\text { inflammatory infiltration. } \\
\text { 2. Enhanced migratory ability of } \\
\text { thymocytes. } \\
\text { 3. Depletion of all subpopulations. } \\
\text { 4. Disorder of selection process. } \\
\text { 5. Formation of granuloma in chronic } \\
\text { infection. }\end{array}$ & $\begin{array}{l}\text { a) Invasion into thymus by yeast. } \\
\text { b) Increase in IL-2, IL-7, IL-17, TNF- } \alpha \text { and AIRE. } \\
\text { c) Higher level of inflammatory cytokines, inflammasome activity and gene expression } \\
\text { of caspase- } 1 \text { and caspase- } 8 \text {. } \\
\text { d) Mature T cells re-entered infected thymus. }\end{array}$ \\
\hline $\begin{array}{l}\text { Aspergillus } \\
\text { fumigatus }\end{array}$ & $(104)$ & Apoptosis of thymocytes. & \\
\hline Fusarium & $(105)$ & Depletion of each subgroup decreased. & \\
\hline Saprolegnia & $(106)$ & Atrophy of fish thymus. & \\
\hline Candida albicans & $(107)$ & Apoptosis of thymocytes. & $\begin{array}{l}\text { C. Albicans FLO8-deficient (flo8) mutant enhances the production of IL-10 by dendritic } \\
\text { cells and macrophage to attenuate apoptosis of T cells. }\end{array}$ \\
\hline
\end{tabular}


(174), which reveals that auto-immune disease and thymic atrophy may be linked in a vicious cycle, leading to the disorder of immune tolerance. Double negative (DN) thymocytes are the main apoptotic cluster although other clusters are involved as well. CD4+ SP thymocytes are depleted in Plasmodium yoelii infected models (95). Both CD4+ and CD8+ SP thymocytes, as well as $\delta \gamma+\mathrm{T}$ cells, are depleted in Plasmodium chabaudi infected models (94). The structure of the thymus and the changes in its composition due to thymic atrophy are shown in Figure 1. Recently, novel research sought to determine subpopulations of thymic atrophy under different insults, including injection with Salmonella Typhimurium, lipopolysaccharide (LPS) and two other non-infectious insults (etoposide and dexamethasone). In this research, all these insults led to depletion of DP cells. However, DN cells and $\mathrm{CD} 8^{+} \mathrm{CD} 3^{\text {lo }}$ immature SP cells were only vulnerable to infection, LPS and etoposide, but not to dexamethasone. The mature SP thymocytes were reduced by the insults of etoposide and dexamethasone, but infection did not affect this process (175). Although the link between the mechanism and target subpopulation of thymic atrophy is not yet clear, researchers are certain that different pathogens induce thymic atrophy in different ways.

Atrophy is defined as shrinkage of the volume of a parenchyma together with decrease of the number of parenchyma cells. Cell death occurs through different mechanisms, including necrosis (passive and uncontrolled cell death) and apoptosis (active and programmed cell death) (176). Apoptosis is the main mechanism of infection-induced thymic atrophy. For example, apoptosis of CD3+ thymocyte is observed in PRRSV (21). Necrosis also plays a small role in infection-induced thymic atrophy, which is reported in NDV, F. tularensis and administration of cholera toxin (CT) or heat-labile enterotoxin (LT) $(78,121,122)$. It should be noted that other types of cellular death are involved in thymic atrophy. Inflammasome activity and gene expression of caspase- 1 in Paracoccidioides brasiliensis indicates that pyroptosis participates in the induction of thymic atrophy (103). Autophagy, a kind of multistep lysosomal degradation pathway, is observed in the HPPRRSV (HuN4) infection model (23).

Although many pathogens can cause thymic atrophy, the mechanisms through which they fulfill this process are quite different. To date, many mechanisms have been demonstrated to be involved in this pathogenic process and conclusions in this regard are shared in Figure 2.

Glucocorticoid secretion is a responsive effect initiated by stress. It has been reported in other models that corticoids can cause lymphocyte depletion. Compared with osteopontin (OPN) (-/-) mice, OPN $(+/+)$ mice showed thymic and splenic atrophy by modulation of corticosterone via the OPN signaling pathway (177). Glucocorticoid hormone level is also thought to be related to infection-induced thymic atrophy. Steroids can trigger apoptosis in thymocytes, in which DP thymocytes are the most sensitive to glucocorticoids (18). This could easily explain why the phenotype of the major apoptotic cluster is CD4+CD8+ thymocytes. SP thymocytes rely on CD28 signaling to be more resistant to glucocorticoid-induced apoptosis (18). In several bacteriaassociated infections, such as sepsis, Salmonella Typhimurium and

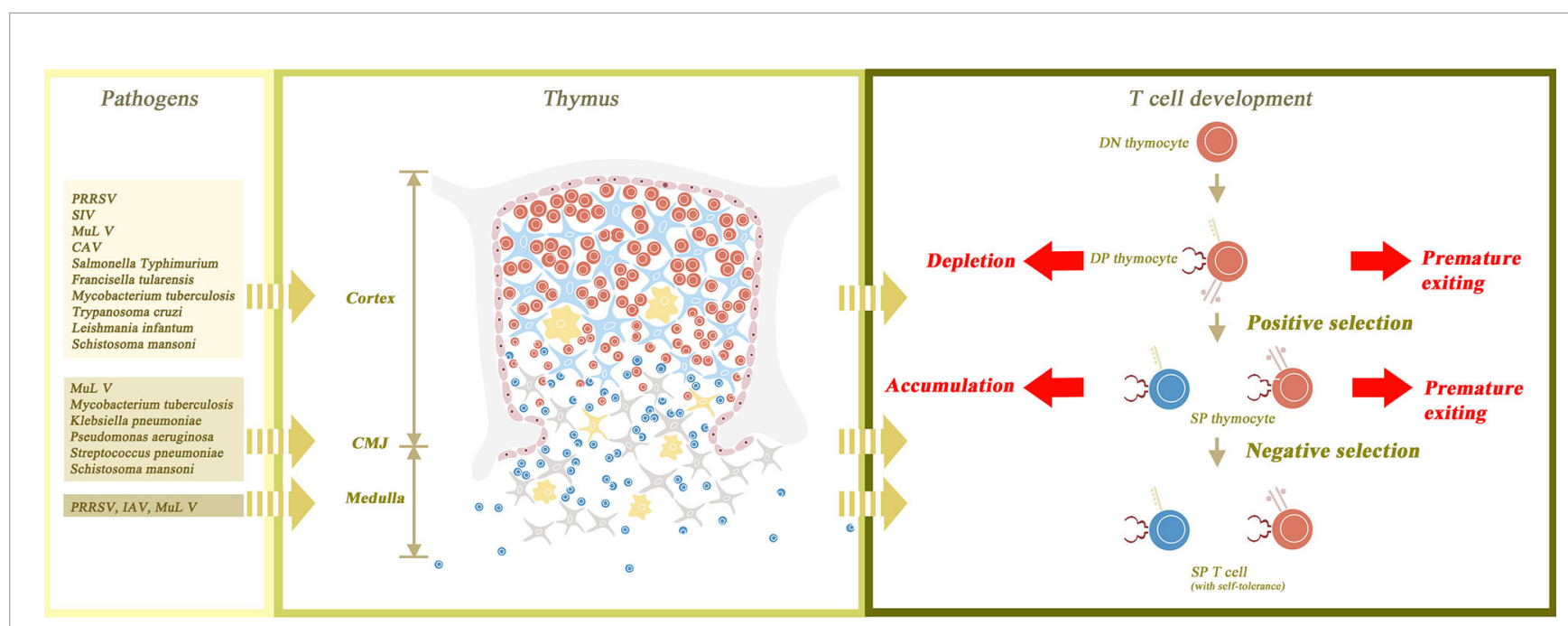

FIGURE 1 | The normal structure of the thymus gland and the changes that occur with atrophy. The thymus parenchyma is composed of cortex and medulla, which are separated by cortico-medullary junction (CMJ). The cortex is constructed from thymic epithelial cells (TEC) as its framework and thymocytes filling in the interspace. The medulla is composed of TECs, naive T cells and macrophages. The process of T cell maturation begins with the transformation of double negative (DN) thymocytes to double positive (DP) thymocytes in the outer cortex of the thymus gland. DP thymocytes then undergo positive and negative selection in the inner cortex and medulla, respectively, to become self-tolerant single positive (SP) thymocytes. Finally, SP thymocytes mature and are transported to peripheral lymphoid tissues. Thymic atrophy leads to the destruction of thymus structure and abnormal maturation of thymocytes. In thymic atrophy, the medullary structure is destroyed and the $\mathrm{CMJ}$ is disappeared, so both positive and negative selection are interrupted. Without positive selection, premature exiting of DP thymocytes may occur. Without negative selection, the autoreactive T cells may have the opportunity to migrate out of the thymus. In addition, cortical structural disorders not only cause the depletion of a large number of DP thymocytes, but also delay the maturation of SP thymocytes, leading to the accumulation of SP thymocytes. Besides, the figure also shows the main affected sites of thymus corresponding to different pathogens. 


\section{Hormones}

\section{Pathogenic direct action}

\author{
Stress \\ $\downarrow$
}

HPA axis

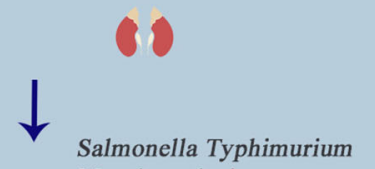

GC M. tuberculosis

T. cruzi,

A. cantonensis

Other involved hormones:

Prolactin, testosterone, DHEA, estradiol, growth hormone, thyroid hormone

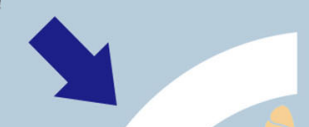

phylococcus,

A. cantonensis

F. tularensis

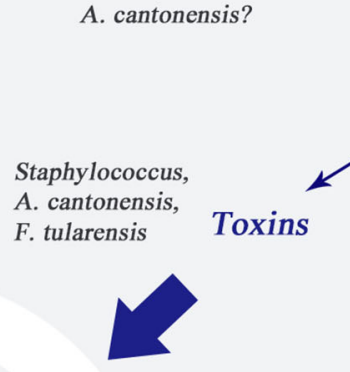

Virus

\section{Exosomes}

A. cantonensis?

\section{Invade via receptors}

PRRSV

$M H V$

F. tularensis

\section{Thymic atrophy}

$\begin{array}{cll}\text { IL-10 } \uparrow & \text { IFN- } \gamma \uparrow & \text { TNF- } \alpha \uparrow \\ \text { PRRSV } & \text { PRRSV, IAV, } & \text { PRRSV, LCMV } \\ \text { Streptococcus suis } & \text { Salmonella Typhimurium } & \text { Salmonella Typhimurium } \\ & \text { T. cruzi } & \text { Mycobacterium tuberculosis } \\ & & \text { Paracoccidioides brasiliensis } \\ \text { Chemotactic factor alteration } & \text { T. cruzi } \\ \text { P. berghei } & \text { Mesenchymal cells alteration } \\ \text { Gut microbiota } & \text { Simian-Human Immunodeficiency Virus } \\ \text { P. berghei }\end{array}$

\section{Microenvironment alteration}

FIGURE 2 | Mechanisms of infection-induced thymic atrophy. This figure summarizes the three main mechanisms of infection-related thymic atrophy and lists the characteristic pathogens corresponding to each mechanism. 1) The hypothalamic-pituitary-adrenal (HPA) axis plays an important role in infection-induced thymic atrophy. Glucocorticoids can induce apoptosis of thymocytes, especially DP thymocytes. In addition, other hormones mentioned in the picture are also thought to be involved in thymic atrophy. 2) At the molecular level, the change of thymus microenvironment is one of the major changes associated with thymic atrophy, and the main cytokines involved are IL-10, IFN- $\gamma$ and TNF- $\alpha$. 3) Some pathogens take the thymus as the target organ and directly invade the thymus. In addition, the products of pathogens, such as toxins, soluble antigens, and exosomes, can also play an important role in thymic atrophy.

tuberculosis, elevation in glucocorticoids is observed. In Chagas disease, glucocorticoids induce thymic atrophy, which can be countered by dehydroepiandrosterone $(155,156)$ and prolactin (154). The HPA axis has been reported to participate in Angiostrongylus cantonensis induced thymic atrophy (96).
The thymic micro-environment alteration is one of the main alterations at molecular level that accompanies thymic atrophy. Elevation of IL-10 was observed in PRRSV and Streptococcus suis, while elevation of IFN- $\gamma$ was observed in PRRSV, IAV, Salmonella Typhimurium and Trypanosoma cruzi. IL-10 
elevation is associated with thymic atrophy, while neem leaf glycoprotein (NLGP) can reverse tumor- and ageassociated thymic atrophy through downregulating IL-10 (178). Type I IFN in chronic LCMV infection has been shown to trigger severe thymic depletion through signal transducers and activators of transcription 2 (Stat2) signaling (34). TNF- $\alpha$ is elevated in infections of PRRSV, LCMV, Salmonella Typhimurium and bacteria targeting the respiratory system, e.g., Mycobacterium tuberculosis. Trypanosoma cruzi and Paracoccidioides brasiliensis also lead to elevation of TNF- $\alpha$. In the Plasmodium berghei infection model and the CLP model, the alterations of chemotactic factors and chemotactic factor receptors have been reported to be the main changes in the thymic microenvironment. Because the interactions between chemotactic factor ligands and their receptors play an important role in T-cell maturation, location and homing, the alterations of these interactions lead to $\mathrm{T}$ cell dysfunction. Some pathogen-induced thymic atrophy causes alteration of mesenchymal and parenchymal cells. Increased expression of ECM component is detected in Plasmodium berghei infection. Destruction of thymic lobar tissue (and replacement of connective tissue) is observed in the infection of SimianHuman Immunodeficiency Virus. Mesenchymal cells function as the regulator of thymocyte location, adhesion and migration. The dysfunction of mesenchymal cells results in a disordered pattern of thymocyte arrangement.

In addition to changes in the thymus microenvironment (i.e. pathogens do not directly attack the thymus), many other pathogens directly target the thymus. PRRSV invades the thymus directly. However, infected cells are depleted via autophagy not apoptosis (23). In MHV infection models, thymocytes replicating virus nucleotides are depleted in a manner of apoptosis (51). Methods to verify that the thymus is the target organ of certain viruses are either through demonstrating the replicating phenomena in the thymus or through purifying the receptors for viral invasion from the thymus. Some scientists use toxins or substances produced from pathogens instead of pathogens themselves for experiments. Interestingly, many components of a pathogen can induce thymic atrophy alone. Lin et al. (77) noted that staphylococcal enterotoxin B (SEB) can lead to thymocyte apoptosis. Similarly, Liu et al. (97) observed that soluble antigen from $A$. cantonensis can lead to apoptosis of thymic stromal cells and thymocytes. In addition, F. tularensis is also found in thymus tissue during infection (78).

Current studies of exosomes have shown that these small vesicles secreted by living cells, have the function of targeting the transport of substances in the vesicles, such as protein, DNA and lncRNA, to specific tissue cells. Exosomes thus play an important role in the information exchange between cells (179). They may be a more effective mediator in the interaction between pathogens and hosts, rather than soluble antigens produced by pathogens. Recent studies show that exosomes can carry bioactive substances and fuse with the host target cells, thus regulating the immune response of the host $(180,181)$ and participating in the pathogenic pathological process (182). Twu et al. found that exosomes originating from Trichomonas vaginalis contained surface proteins and proteases, potentially involved in pathogenesis. This exosome fused with and delivered its content to ectocervical cells, contributing to the adhesion and pathogenesis of Trichomonas vaginalis (183). In a similar fashion, exosomes from Trypanosoma were also found to mediate release of various proteins including some proteases, whose functions include promoting invasion, protecting Trypanosoma from host immunity and affecting physiology of host cells $(184,185)$. Additionally, RNA in exosomes may also play a non-negligible role here. Zhu et al. found that exosomes derived from Schistosoma japonicum and their cargo mi-RNA could be internalized by mammalian cells (186). Exosomes derived from Trypanosoma cruzi can modify some genes of host cells via abundant tRNA-derived small RNAs (187). Exosomes originating from pathogens possess immunestimulatory or inhibitory effects. Wang et al. demonstrated that exosomes originating from S. japonicum promoted M1 macrophage polarization and release of pro-inflammatory factors (188). Oliveira et al. found that incubation of Cryptococcus neoformans vesicles with murine macrophages resulted in increased levels of TNF-alpha, IL-1, and TGF-beta, and stimulated nitric oxide production by phagocytes thus enhancing antimicrobial function (189). Buck et al. discovered that exosomes from Heligmosomoides polygyrus suppressed type 2 innate responses. In mouse cells that are incubated with $H$. polygyrus exosomes, Dusp1, an attenuator of immune activation, is suppressed by miRNA (190). Increasing research evidence indicates the close and complex relationship between host and exosomes originating from pathogens. Interestingly, it is mentioned above that the administration of the soluble antigen of $A$. cantonensis into the thymus of mice can cause obvious thymic atrophy, as for mice directly infected with $A$. cantonensis (97). Given that soluble antigens of $A$. cantonensis may break down during a long journey from the brain to the thymus, we reasonably speculate that the transport of soluble antigens should rely on a more effective vector, with exosomes the suitable choice. Therefore, it is reasonable to infer that some pathogenic products released by pathogens can be precisely transported to the thymus in vivo by means of exosomes, thus leading to apoptosis of thymic cells and TECs. However, to date this is mere speculation and requires further verification by experiments.

Advances in studies of the mechanisms underlying thymic atrophy have led to subsequent proposals about its reversal. Different therapies such as nutritional supplementation (i.e. Zinc, antioxidants), cytokines, chemokines, hormones, and growth factors have been reported to be effective in reversing thymic atrophy (191). However, for infection-induced thymic atrophy, there is less related research at present. Therapeutic methods for infection-induced thymic atrophy are not fully established. In the studies that have been done so far, it is reported that in HIV patients, high dose treatment of $\mathrm{N}$-acetyl cysteine (a prodrug of glutathione) and vitamin C could induce higher numbers of CD4+ T cells (192). Leptin attenuates LPS-induced thymocyte apoptosis by down regulating cPLA2 and p38 MAPK activation (193). In T. cruziinfected mice, melatonin reverts thymic atrophy by increasing 
thymic weight, thymocyte total number and the ratio of DP thymocytes (194). During infections of pathogens, like T. cruzi, glucocorticoids play a vital role in thymic atrophy via activating caspase 8 and caspase 9. The administration of steroid receptor RU486 can reverse this effect of GC in T. cruzi-infected mice (149). However, it cannot be ignored that GC has a protective effect on the host during infection, as the blocking of GC receptor RU486 accelerates host death, which has been demonstrated experimentally (150). Another stress-induced hormone, prolactin, is also known to restrict GC-induced thymic atrophy and can export immature DP thymocytes to the periphery (154). The question of what hormone we can use to manually intervene, and how to regulate them to produce maximum therapeutic results, safely for patients, is worthy of more research. Exosomes may offer distinct potential to reverse thymic atrophy. Recent research has demonstrated that extracellular vesicles isolated from plasma of young mice could increase the longevity and delay inflammaging of old mice (195, 196). Wnt4-transgenic TEC-derived exosomes demonstrated the ability to delay age-related thymic atrophy (197). Moreover, exosomes or extracellular vesicles extracted from juvenile mice could reverse thymic atrophy and decrease the autoimmune reactions (196), indicating that exosome injection as a therapy could be an option. Exosomes produced by pathogens may be used as carriers of pathogenic substances. Thus, it is reasonable to speculate that exosomes in normal human or mouse serum may contain substances that can ameliorate thymic atrophy. Purified normal serum exosomes may provide a new solution for the treatment of thymic atrophy in the future.

To date, limited studies have been conducted on infectioninduced thymic atrophy in humans, and more mechanisms need to be discovered to update existing theories. At present, all studies on the mechanism of infection-induced thymic atrophy focuses on the changes of the thymic microenvironment. And these studies attempted to explain the possible causes of thymic atrophy through the changes in cytokines and hormones in body fluid, while ignoring the possible role of neuromodulation. The regulation of homeostasis in the human body is achieved by the neuro-humoralimmune regulation network. Pathogen infection, as a stressor, will cause a strong stress response, which inevitably involves neuromodulation. The thymus is innervated by both sympathetic and parasympathetic nerves (198). Under long-term stress, sympathetic nerve excitation will make peripheral blood vessels contract violently for a long time to distribute more blood to important organs such as the liver and brain. This may lead to insufficient blood supply to the thymus and induce apoptosis or necrosis. Furthermore, studies have confirmed that the proliferation and function of T cells will be inhibited under the condition of high concentration of catecholamines (199). The sympathetic nervous system is also closely related to the function of the HPA axis under stress (200), suggesting that it may be involved in the HPA-related mechanism of thymic atrophy. In addition, the thymus is innervated by the non-adrenergic and non-cholinergic (NANC) nervous system. In the case of severe infection such as sepsis, NANC releases substance $\mathrm{P}$ and neurokinin $\mathrm{A}$ to increase vascular permeability and inflammatory exudation (201), which may aggravate infection-induced thymic atrophy when these occur in the thymus. It is possible that there are potentially more neurorelated mechanisms to be discovered. Therefore, we suggest that researchers devote more attention to exploring the effects of neuroregulatory mechanisms on infection-induced thymic atrophy in future.

With medical advances, most infections can be controlled in the acute phase. However, chronic infections, often ignored by both doctors and patients, can also have a serious impact on the body, especially in children, whose thymic atrophy may occur ahead of time in the process of chronic infection. For example, chronic oral infections, such as dental caries, gingivitis and periodontitis, are demonstrated to be related to diabetes and preterm birth (202), and immune disorders are involved in their pathogenesis. Periodontitis can lead to type 1 diabetes by mediating decrease in insulin release and insulin resistance through cytokines alteration (203). Moreover, in children, chronic infections may affect the developing repertoire of $\mathrm{T}$ cells (6). Thus, it's necessary to pay more attention to the residual chronic infection while controlling the acute infection. And it is of great significance to enhance the ability to detect the micro-infection in the field of clinical diagnosis and testing. Under chronic infection, the pathogen interacts with the thymus through the mechanisms mentioned above to induce thymic atrophy, and then leads to a series of immune disorders. By summarizing these mechanisms, we hope to provide inspiration for the selection of predictors for early diagnostic models of chronic infection in the future.

As noted above, there are both similarities and differences in the pathologic manifestations of infection-related and agerelated thymic atrophy. Although the mechanism of their occurrence is slightly different at present, whether there is a common downstream pathway is worth further investigation. Therefore, our summary of the mechanisms of infection-induced thymic atrophy may also suggest a potential mechanism for agerelated thymic atrophy. We also summarize possible measures to reverse infection-related thymic atrophy, we hope that researchers will take inspiration from these treatments that target different mechanisms and one day find a way to reverse age-related thymic atrophy and boost the body's immune system.

\section{AUTHOR CONTRIBUTIONS}

ML, LX, and ZQ have contributed equally to this work and share first authorship. XS is the corresponding author. All authors contributed to the article and approved the submitted version.

\section{ACKNOWLEDGMENTS}

This project was supported by the National Key R\&D Program of China (No. 2020YFC1200100), Chinese National Natural Science Foundation (No. 81871682), Natural Science Foundation of Guangdong Province (No. 2019A1515012068), the Pearl River Nova Program of Guangzhou (No. 201710010030), the Fundamental Research Funds for the Central Universities (No. 17ykpy09) and Honor Program for basic Medicine of Sun Yat sen university (2020). 


\section{REFERENCES}

1. Kindt TJ, Goldsby RA, Osborne BA, Kuby J. Kuby Immunology (2007). Available at: https://books.google.com.hk/books?id=oOsFf2WfE5wC.

2. Gascoigne NR, Rybakin V, Acuto O, Brzostek J. Tcr Signal Strength and T Cell Development. Annu Rev Cell Dev Biol (2016) 32:327-48. doi: 10.1146/ annurev-cellbio-111315-125324

3. Cepeda S, Griffith A. Thymic Stromal Cells: Roles in Atrophy and AgeAssociated Dysfunction of the Thymus. Exp Gerontol (2018) 105:113-7. doi: 10.1016/j.exger.2017.12.022

4. Fraker P, King L. Reprogramming of the Immune System During Zinc Deficiency. Annu Rev Nutr (2004) 24:277-98. doi: 10.1146/ annurev.nutr.24.012003.132454

5. Savino W, Dardenne M. Nutritional Imbalances and Infections Affect the Thymus: Consequences on T-cell-mediated Immune Responses. Proc Nutr Soc (2010) 69(4):636-43. doi: 10.1017/s0029665110002545

6. Nunes-Alves C, Nobrega C, Behar SM, Correia-Neves M. Tolerance has its Limits: How the Thymus Copes With Infection. Trends Immunol (2013) Oct34(10):502-10. doi: 10.1016/j.it.2013.06.004

7. Aspinall R, Andrew D. Thymic Involution in Aging. J Clin Immunol (2000) 20(4):250-6. doi: 10.1023/a:1006611518223

8. Carrio R, Torroella-Kouri M, Iragavarapu-Charyulu V, Lopez DM. TumorInduced Thymic Atrophy: Alteration in Interferons and Jak/Stats Signaling Pathways. Int J Oncol (2011) 38(2):547-53. doi: 10.3892/ijo.2010.870

9. Thomas R, Wang W, Su DM. Contributions of Age-Related Thymic Involution to Immunosenescence and Inflammaging. Immun Ageing (2020) 17:2. doi: 10.1186/s12979-020-0173-8

10. Gruver A, Hudson L, Sempowski G. Immunosenescence of Ageing. J Pathol (2007) 211(2):144-56. doi: 10.1002/path.2104

11. O'Sullivan BJ, Yekollu S, Ruscher R, Mehdi AM, Maradana MR, Chidgey AP, et al. Autoimmune-Mediated Thymic Atrophy Is Accelerated But Reversible in RelB-Deficient Mice. Front Immunol (2018) 9:1092. doi: 10.3389/fimmu.2018.01092

12. Aspinall R, Andrew D. Immunosenescence: Potential Causes and Strategies for Reversal. Biochem Soc Trans (2000) 28(2):250-4. doi: 10.1042/bst0280250

13. Rehman S, Majeed T, Azam Ansari M, Ali U, Sabit H, Al-Suhaimi E. Current Scenario of COVID-19 in Pediatric Age Group and Physiology of Immune and Thymus Response. Saudi J Biol Sci (2020) 27(10):2567-73. doi: 10.1016/ j.sjbs.2020.05.024

14. Lins MP, Smaniotto S. Potential Impact of SARS-CoV-2 Infection on the Thymus. Can J Microbiol (2021) 67(1):23-8. doi: 10.1139/cjm-2020-0170\% M32640169

15. Sato Y, Yanagita M. Immunology of the Ageing Kidney. Nat Rev Nephrol (2019) 15(10):625-40. doi: 10.1038/s41581-019-0185-9

16. Nikolich-Žugich J. The Twilight of Immunity: Emerging Concepts in Aging of the Immune System. Nat Immunol (2018) 19(1):10-9. doi: 10.1038/ s41590-017-0006-x

17. Palmer S, Albergante L, Blackburn CC, Newman TJ. Thymic Involution and Rising Disease Incidence With Age. Proc Natl Acad Sci U S A (2018) 115 (8):1883-8. doi: 10.1073/pnas.1714478115

18. Savino W. The Thymus is a Common Target Organ in Infectious Diseases. PloS Pathog (2006) 2(6):e62. doi: 10.1371/journal.ppat.0020062

19. Aspinall R. Age-Associated Thymic Atrophy in the Mouse is Due to a Deficiency Affecting Rearrangement of the TCR During Intrathymic T Cell Development. J Immunol (1997) Apr 1158(7):3037-45.

20. Tyan ML. Age-Related Decrease in Mouse T Cell Progenitors. J Immunol (1977) 118(3):846-51.

21. Amarilla SP, Gomez-Laguna J, Carrasco L, Rodriguez-Gomez IM, Caridad YOJ, Graham SP, et al. Thymic Depletion of Lymphocytes is Associated With the Virulence of PRRSV-1 Strains [Journal Article]. Vet Microbiol (2016) 188:47-58. doi: 10.1016/j.vetmic.2016.04.005\%/ Copyright (c) 2016 Elsevier B.V

22. He Y, Wang G, Liu Y, Shi W, Han Z, Wu J, et al. Characterization of Thymus Atrophy in Piglets Infected With Highly Pathogenic Porcine Reproductive and Respiratory Syndrome Virus. Vet Microbiol (2012) 160(3-4):455-62. doi: 10.1016/j.vetmic.2012.05.040

23. Wang G, Yu Y, Tu Y, Tong J, Liu Y, Zhang C, et al. Highly Pathogenic Porcine Reproductive and Respiratory Syndrome Virus Infection Induced
Apoptosis and Autophagy in Thymi of Infected Piglets. PloS One (2015) 10 (6):e0128292. doi: 10.1371/journal.pone.0128292

24. Wang G, Song T, Yu Y, Liu Y, Shi W, Wang S, et al. Immune Responses in Piglets Infected With Highly Pathogenic Porcine Reproductive and Respiratory Syndrome Virus. Vet Immunol Immunopathol (2011) 142(34):170-8. doi: 10.1016/j.vetimm.2011.05.004

25. Ruedas-Torres I, Rodríguez-Gómez IM, Sánchez-Carvajal JM, Pallares FJ, Barranco I, Carrasco L, et al. Activation of the Extrinsic Apoptotic Pathway in the Thymus of Piglets Infected With PRRSV-1 Strains of Different Virulence. Vet Microbiol (2020) 243:108639. doi: 10.1016/j.vetmic.2020.108639

26. Romero-Palomo F, Risalde MA, Molina V, Lauzi S, Bautista MJ, GomezVillamandos JC. Characterization of Thymus Atrophy in Calves With Subclinical BVD Challenged With BHV-1. Vet Microbiol (2015) 177(12):32-42. doi: 10.1016/j.vetmic.2015.02.018. Cited in: Pubmed

27. M K, K T, M V, T HJ, R T. CD46 is a Cellular Receptor for Bovine Viral Diarrhea Virus. J Virol (2004) 78(4):1792-9. doi: 10.1128/jvi.78.4.17921799.2004

28. Duan X, Lu J, Zhou K, Wang J, Wu J, Gao GF, et al. NK-Cells are Involved in Thymic Atrophy Induced by Influenza A Virus Infection. J Gen Virol (2015) 96(11):3223-35. doi: 10.1099/jgv.0.000276

29. Silvano FD, Kanata Y, Takeuchi M, Shimada A, Otsuki K, Umemura T. Avian Influenza A Virus Induced Stunting Syndrome-Like Disease in Chicks. J Vet Med Sci (1997) 59(3):205-7. doi: 10.1292/jvms.59.205

30. Liu B, Zhang X, Deng W, Liu J, Li H, Wen M, et al. Severe Influenza A (H1N1)pdm09 Infection Induces Thymic Atrophy Through Activating Innate CD8(+)CD44(Hi) T Cells by Upregulating IFN-Gamma. Cell Death Dis (2014) 5:e1440. doi: 10.1038/cddis.2014.323

31. Berg LJ. Signalling Through TEC Kinases Regulates Conventional Versus Innate CD8(+) T-Cell Development. Nat Rev Immunol (2007) 7(6):479-85. doi: 10.1038/nri2091

32. Liu B, Bao L, Wang L, Li F, Wen M, Li H, et al. Anti-IFN- $\gamma$ Therapy Alleviates Acute Lung Injury Induced by Severe Influenza A (H1n1) pdm09 Infection in Mice. J Microbiol Immunol Infect (2019) S1684-1182 (18):30438-9. doi: 10.1016/j.jmii.2019.07.009. Cited in: Pubmed

33. Hassan KE, Ali A, Shany SAS, El-Kady MF. Experimental Co-Infection of Infectious Bronchitis and Low Pathogenic Avian Influenza H9N2 Viruses in Commercial Broiler Chickens. Res Vet Sci (2017) 115:356-62. doi: 10.1016/ j.rvsc.2017.06.024

34. Elsaesser HJ, Mohtashami M, Osokine I, Snell LM, Cunningham CR, Boukhaled GM, et al. Chronic Virus Infection Drives CD8 T CellMediated Thymic Destruction and Impaired Negative Selection. Proc Natl Acad Sci U S A (2020) 117(10):5420-9. doi: 10.1073/pnas.1913776117

35. Orange JS, Salazar-Mather TP, Opal SM, Spencer RL, Miller AH, McEwen BS, et al. Mechanism of Interleukin 12-Mediated Toxicities During Experimental Viral Infections: Role of Tumor Necrosis Factor and Glucocorticoids. J Exp Med (1995) 181(3):901-14. doi: 10.1084/jem.181.3.901

36. Muller JG, Krenn V, Czub S, Stahl-Hennig C, Coulibaly C, Hunsmann G, et al. The Thymic Epithelial Reticulum and Interdigitating Cells in SIVinduced Thymus Atrophy and its Comparison With Other Forms of Thymus Involution. Res Virol (1993) 144(1):93-8. doi: 10.1016/s0923-2516 (06) $80017-8$

37. Sodora D, Milush J, Ware F, Wozniakowski A, Montgomery L, McClure H, et al. Decreased Levels of Recent Thymic Emigrants in Peripheral Blood of Simian Immunodeficiency Virus-Infected Macaques Correlate With Alterations Within the Thymus. J Virol (2002) 76(19):9981-90. doi: 10.1128/jvi.76.19.9981-9990.2002

38. Stephens EB, McCormick C, Pacyniak E, Griffin D, Pinson DM, Sun F, et al. Deletion of the Vpu Sequences Prior to the Env in a Simian-Human Immunodeficiency Virus Results in Enhanced Env Precursor Synthesis But is Less Pathogenic for Pig-Tailed Macaques [Comparative Study; Journal Article; Research Support, U.S. Gov't, P.H.s.]. Virology (2002) 293 (2):252-61. doi: 10.1006/viro.2001.1244

39. Fiume G, Scialdone A, Albano F, Rossi A, Tuccillo FM, Rea D, et al. Impairment of $\mathrm{T}$ Cell Development and Acute Inflammatory Response in HIV-1 Tat Transgenic Mice. Sci Rep (2015) 5:13864. doi: 10.1038/srep13864

40. Tesselaar K, Miedema F. Growth Hormone Resurrects Adult Human Thymus During HIV-1 Infection. J Clin Invest (2008) 118(3):844-7. doi: $10.1172 /$ jci35112 
41. Diehl LJ, Mathiason-Dubard CK, O'Neil LL, Obert LA, Hoover EA. Induction of Accelerated Feline Immunodeficiency Virus Disease by Acute-Phase Virus Passage. J Virol (1995) 69(10):6149-57. doi: 10.1128/ JVI.69.10.6149-6157.1995

42. Johnson CM, Bortnick SJ, Crawford PC, Papadi GP. Unique Susceptibility of the Fetal Thymus to Feline Immunodeficiency Virus Infection: An Animal Model for HIV Infection In Utero. Am J Reprod Immunol (2001) 45(5):27388. doi: $10.1111 / \mathrm{j} .8755-8920.2001 .450503 . x$

43. Hayasaka D, Ennis FA, Terajima M. Pathogeneses of Respiratory Infections With Virulent and Attenuated Vaccinia Viruses. Virol J (2007) 4:22. doi: $10.1186 / 1743-422 x-4-22$

44. R PC, M JB, S GL. Steroid Hormone Synthesis by Vaccinia Virus Suppresses the Inflammatory Response to Infection. J Exp Med (2003) 197(10):1269-78. doi: 10.1084/jem.20022201

45. Chen X, Da R, Jin X, Song W, Li X, Fu Y, et al. Cross-Species Infectivity and Pathogenesis of the Friend Murine Leukemia Virus Complex in Syrian Hamsters. Virus Res (2007) 130(1-2):281-4. doi: 10.1016/j.virusres. 2007.05.015

46. Bonzon C, Fan H. Moloney Murine Leukemia Virus-Induced Preleukemic Thymic Atrophy and Enhanced Thymocyte Apoptosis Correlate With Disease Pathogenicity. J Virol (1999) 73(3):2434-41. doi: 10.1128/ JVI.73.3.2434-2441.1999

47. de Leval L, Deprez M, Colombi S, Humblet C, Defresne MP, Boniver J, et al. Morphological Changes of Thymus in Retrovirus-Induced Murine Acquired Immunodeficiency Syndrome (MAIDS). Pathol Res Pract (1995) 191 (6):506-12. doi: 10.1016/s0344-0338(11)80869-1

48. Haridy M, Sasaki J, Ikezawa M, Okada K, Goryo M. Pathological and Immunohistochemical Studies of Subclinical Infection of Chicken Anemia Virus in 4-Week-Old Chickens. J Vet Med Sci (2012) 74(6):757-64. doi: 10.1292/jvms.11-0374

49. Castano P, Benavides J, Lee MS, Fernandez M, Fuertes M, Royo M, et al. Tissue Tropism of Chicken Anaemia Virus in Naturally Infected Broiler Chickens. J Comp Pathol (2019) 167:32-40. doi: 10.1016/j.jcpa.2018.11.008

50. Shawky S, Sandhu T, Shivaprasad HL. Pathogenicity of a Low-Virulence Duck Virus Enteritis Isolate With Apparent Immunosuppressive Ability. Avian Dis (2000) 44(3):590-9. doi: 10.2307/1593098

51. Godfraind C, Holmes KV, Coutelier JP. Thymus Involution Induced by Mouse Hepatitis Virus A59 in BALB/c Mice. J Virol (1995) 69(10):6541-7. doi: 10.1128/JVI.69.10.6541-6547.1995

52. Munoz-Gonzalez S, Ruggli N, Rosell R, Perez LJ, Frias-Leuporeau MT, Fraile L, et al. Postnatal Persistent Infection With Classical Swine Fever Virus and its Immunological Implications. PloS One (2015) 10(5):e125692. doi: 10.1371/journal.pone.0125692

53. Fu Q, Huang Y, Wan C, Fu G, Qi B, Cheng L, et al. Genomic and Pathogenic Analysis of a Muscovy Duck Parvovirus Strain Causing Short Beak and Dwarfism Syndrome Without Tongue Protrusion. Res Vet Sci (2017) 115:393-400. doi: 10.1016/j.rvsc.2017.07.006

54. Ezema WS, Eze DC, Shoyinka SV, Okoye JO. Atrophy of the Lymphoid Organs and Suppression of Antibody Response Caused by Velogenic Newcastle Disease Virus Infection in Chickens. Trop Anim Health Prod (2016) 48(8):1703-9. doi: 10.1007/s11250-016-1147-x

55. Okpe GC, Ezema WS, Shoyinka SV, Okoye JO. Vitamin A Dietary Supplementation Reduces the Mortality of Velogenic Newcastle Disease Significantly in Cockerels. Int J Exp Pathol (2015) 96(5):326-31. doi: 10.1111/iep.12138

56. Berthault C, Larcher T, Hartle S, Vautherot JF, Trapp-Fragnet L, Denesvre C. Atrophy of Primary Lymphoid Organs Induced by Marek's Disease Virus During Early Infection is Associated With Increased Apoptosis, Inhibition of Cell Proliferation and a Severe B-Lymphopenia. Vet Res (2018) 49(1):31. doi: 10.1186/s13567-018-0526-x

57. Perry L, Hotchkiss J, Lodmell D. Murine Susceptibility to Street Rabies Virus is Unrelated to Induction of Host Lymphoid Depletion. I Immunol (Baltimore Md 1950) (1990) 144(9):3552-7.

58. Cardenas Palomo L, de Souza Matos D, Chaves Leal E, Bertho A, Marcovistz R. Lymphocyte Subsets and Cell Proliferation Analysis in Rabies-Infected Mice. J Clin Lab Immunol (1995) 46(2):49-61.

59. Yang D, Zhao C, Zhang M, Zhang S, Zhai J, Gao X, et al. Changes in Oxidation-Antioxidation Function on the Thymus of Chickens Infected
With Reticuloendotheliosis Virus. BMC Vet Res (2020) 16(1):483. doi: 10.1186/s12917-020-02708-6

60. Baily JL, Willoughby K, Maley M, Chapman J, Pizzi R, Hall AJ, et al. Widespread Neonatal Infection With Phocid Herpesvirus 1 in Free-Ranging and Stranded Grey Seals Halichoerus Grypus. Dis Aquat Organ (2019) 133 (3):181-7. doi: 10.3354/dao03345

61. Deobagkar-Lele M, Chacko SK, Victor ES, Kadthur JC, Nandi D. InterferonGamma- and Glucocorticoid-Mediated Pathways Synergize to Enhance Death of CD4(+) CD8(+) Thymocytes During Salmonella Enterica Serovar Typhimurium Infection. Immunology (2013) 138(4):307-21. doi: $10.1111 / \mathrm{imm} .12047$

62. Majumdar S, Deobagkar-Lele M, Adiga V, Raghavan A, Wadhwa N, Ahmed SM, et al. Differential Susceptibility and Maturation of Thymocyte Subsets During Salmonella Typhimurium Infection: Insights on the Roles of Glucocorticoids and Interferon-Gamma. Sci Rep (2017) 7:40793. doi: 10.1038/srep40793. Cited in: Pubmed

63. Deobagkar-Lele M, Victor ES, Nandi D. C-Jun NH2 -Terminal Kinase is a Critical Node in the Death of CD4+ CD8+ Thymocytes During Salmonella Enterica Serovar Typhimurium Infection. Eur J Immunol (2014) 44(1):13749. doi: 10.1002/eji.201343506

64. Huang H, Liu A, Wu H, Ansari AR, Wang J, Huang X, et al. Transcriptome Analysis Indicated That Salmonella Lipopolysaccharide-Induced Thymocyte Death and Thymic Atrophy Were Related to TLR4-FOS/JUN Pathway in Chicks. BMC Genomics (2016) 17:322. doi: 10.1186/s12864-016-2674-6

65. Ross EA, Coughlan RE, Flores-Langarica A, Lax S, Nicholson J, Desanti GE, et al. Thymic Function is Maintained During Salmonella-induced Atrophy and Recovery. J Immunol (2012) 189(9):4266-74. doi: 10.4049/ jimmunol.1200070

66. Majumdar S, Mishra V, Nandi S, Abdullah M, Barman A, Raghavan A, et al. Absence of Receptor Guanylyl Cyclase C Enhances Ileal Damage and Reduces Cytokine and Antimicrobial Peptide Production During Oral Salmonella Enterica Serovar Typhimurium Infection. Infect Immun (2018) 86(5):e00799-17. doi: 10.1128/iai.00799-17

67. Sempowski GD, Rhein ME, Scearce RM, Haynes BF. Leukemia Inhibitory Factor is a Mediator of Escherichia Coli Lipopolysaccharide-Induced Acute Thymic Atrophy. Eur J Immunol (2002) 32(11):3066-70. doi: 10.1002/15214141(200211)32:11<3066::Aid-immu3066>3.0.Co;2-j

68. Norimatsu M, Ono T, Aoki A, Ohishi K, Tamura Y. In-Vivo Induction of Apoptosis in Murine Lymphocytes by Bacterial Lipopolysaccharides. J Med Microbiol (1995) 43(4):251-7. doi: 10.1099/00222615-43-4-251

69. Chisari FV, Northrup RS. Pathophysiologic Effects of Lethal and Immunoregulatory Doses of Cholera Enterotoxin in the Mouse. J Immunol (1974) 113(3):740-9.

70. Hussain A, Himeno K, Mayumi H, Kawamura I, Tsuru S, Nomoto K. Immunomodulatory Effects of Cholera Toxin in Mice. Nat Immun Cell Growth Regul (1989) 8(4):231-44.

71. Tsuji T, Asano Y, Handa T, Honma Y, Ichinose Y, Yokochi T. Induction of Apoptosis in Lymphoid Tissues of Mice After Intramuscular Injection of Enterotoxigenic Escherichia Coli Enterotoxin. Immunobiology (2000) 201(34):377-90. doi: 10.1016/s0171-2985(00)80092-3

72. Kuchler L, Sha LK, Giegerich AK, Knape T, Angioni C, Ferreiros N, et al. Elevated Intrathymic sphingosine-1-phosphate Promotes Thymus Involution During Sepsis. Mol Immunol (2017) 90:255-63. doi: 10.1016/ j.molimm.2017.08.011

73. Kong Y, Li Y, Zhang W, Yuan S, Winkler R, Krohnert U, et al. SepsisInduced Thymic Atrophy Is Associated With Defects in Early Lymphopoiesis. Stem Cells (2016) 34(12):2902-15. doi: 10.1002/stem.2464

74. Wang S, Lyu C, Duan G, Meng F, Yang Y, Yu Y, et al. Streptococcus Suis Serotype 2 Infection Causes Host Immunomodulation Through Induction of Thymic Atrophy. Infect Immun (2020) 88(4):e00950-19. doi: 10.1128/ iai.00950-19

75. Starikova EA, Golovin AS, Vasilyev KA, Karaseva AB, Serebriakova MK, Sokolov AV, et al. Role of Arginine Deiminase in Thymic Atrophy During Experimental Streptococcus Pyogenes Infection. Scand J Immunol (2019) 89 (2):e12734. doi: $10.1111 /$ sji.12734

76. Chen L-y, Ming J, Shui-ping L, Xue-jun Y. Apoptosis of Mouse Thymocytes and Its Gene Regulation Induced by Listeria Monocytogenesis. Shanghai $J$ Immunol (2001) 06):327-329+333. 
77. Lin YS, Huang YT, Chen PS, Lin CF, Jan MS, Lei HY. Requirement of I-E Molecule for Thymocyte Apoptosis Induced by Staphylococcal Enterotoxin B In Vivo. Cell Immunol (1999) 193(1):71-9. doi: 10.1006/cimm.1998.1442

78. Chen W, Kuolee R, Austin JW, Shen H, Che Y, Conlan JW. Low Dose Aerosol Infection of Mice With Virulent Type A Francisella Tularensis Induces Severe Thymus Atrophy and CD4+CD8+ Thymocyte Depletion. Microb Pathog (2005) 39(5-6):189-96. doi: 10.1016/j.micpath.2005.08.005

79. Lin YS, Chen KH, Kuo CF, Huang KJ, Wu JJ. Induction of Thymocyte Apoptosis in Mice by Yersinia Enterocolitica Products. J Med Microbiol (1998) 47(5):447-54. doi: 10.1099/00222615-47-5-447

80. Abramov VM, Kosarev IV, Motin VL, Khlebnikov VS, Vasilenko RN, Sakulin VK, et al. Binding of LcrV Protein From Yersinia Pestis to Human T-cells Induces Apoptosis, Which is Completely Blocked by Specific Antibodies. Int J Biol Macromol (2019) 122:1062-70. doi: 10.1016/ j.ijbiomac.2018.09.054

81. Borges M, Barreira-Silva P, Florido M, Jordan MB, Correia-Neves M, Appelberg R. Molecular and Cellular Mechanisms of Mycobacterium Avium-Induced Thymic Atrophy. J Immunol (2012) 189(7):3600-8. doi: 10.4049/jimmunol.1201525

82. Bottasso O, Bay ML, Besedovsky H, del Rey A. The Immuno-Endocrine Component in the Pathogenesis of Tuberculosis. Scand J Immunol (2007) 66 (2-3):166-75. doi: 10.1111/j.1365-3083.2007.01962.x

83. Ozeki Y, Kaneda K, Fujiwara N, Morimoto M, Oka S, Yano I. In Vivo Induction of Apoptosis in the Thymus by Administration of Mycobacterial Cord Factor (Trehalose 6,6'-Dimycolate). Infect Immun (1997) 65(5):17939. doi: 10.1128/IAI.65.5.1793-1799.1997

84. Wang SD, Huang KJ, Lin YS, Lei HY. Sepsis-Induced Apoptosis of the Thymocytes in Mice. J Immunol (1994) 152(10):5014-21.

85. Perez AR, Berbert LR, Lepletier A, Revelli S, Bottasso O, Silva-Barbosa SD, et al. TNF-Alpha is Involved in the Abnormal Thymocyte Migration During Experimental Trypanosoma Cruzi Infection and Favors the Export of Immature Cells. PloS One (2012) 7(3):e34360. doi: 10.1371/journal.pone.0034360

86. de Meis J, Morrot A, Farias-de-Oliveira DA, Villa-Verde DM, Savino W. Differential Regional Immune Response in Chagas Disease. PloS Negl Trop Dis (2009) 3(7):e417. doi: 10.1371/journal.pntd.0000417

87. Roggero E, Del Rey A, Wildmann J, Besedovsky H. Glucocorticoids and Sympathetic Neurotransmitters Modulate the Acute Immune Response to Trypanosoma Cruzi. Ann N Y Acad Sci (2019) 1437(1):83-93. doi: 10.1111/ nyas. 13946

88. Carbajosa S, Gea S, Chillón-Marinas C, Poveda C, Del Carmen Maza M, Fresno M, et al. Altered Bone Marrow Lymphopoiesis and interleukin-6dependent Inhibition of Thymocyte Differentiation Contribute to Thymic Atrophy During Trypanosoma Cruzi Infection. Oncotarget (2017) 8 (11):17551-61. doi: 10.18632/oncotarget.14886

89. Losada-Barragan M, Umana-Perez A, Duraes J, Cuervo-Escobar S, Rodriguez-Vega A, Ribeiro-Gomes FL, et al. Thymic Microenvironment is Modified by Malnutrition and Leishmania Infantum Infection. Front Cell Infect Microbiol (2019) 9:252. doi: 10.3389/fcimb.2019.00252

90. Losada-Barragan M, Umana-Perez A, Cuervo-Escobar S, Berbert LR, Porrozzi R, Morgado FN, et al. Protein Malnutrition Promotes Dysregulation of Molecules Involved in T Cell Migration in the Thymus of Mice Infected With Leishmania Infantum. Sci Rep (2017) 7:45991. doi: $10.1038 /$ srep45991

91. Andrade CF, Gameiro J, Nagib PR, Carvalho BO, Talaisys RL, Costa FT, et al. Thymic Alterations in Plasmodium Berghei-Infected Mice. Cell Immunol (2008) 253(1-2):1-4. doi: 10.1016/j.cellimm.2008.06.001

92. Francelin C, Paulino LC, Gameiro J, Verinaud L. Effects of Plasmodium Berghei on Thymus: High Levels of Apoptosis and Premature Egress of CD4 (+)CD8(+) Thymocytes in Experimentally Infected Mice. Immunobiology (2011) 216(10):1148-54. doi: 10.1016/j.imbio.2011.03.009

93. Gameiro J, Nagib PR, Andrade CF, Villa-Verde DM, Silva-Barbosa SD, Savino W, et al. Changes in Cell Migration-Related Molecules Expressed by Thymic Microenvironment During Experimental Plasmodium Berghei Infection: Consequences on Thymocyte Development. Immunology (2010) 129(2):248-56. doi: 10.1111/j.1365-2567.2009.03177.x

94. Seixas E, Ostler D. Plasmodium Chabaudi Chabaudi (as): Differential Cellular Responses to Infection in Resistant and Susceptible Mice. Exp Parasitol (2005) 110(4):394-405. doi: 10.1016/j.exppara.2005.03.024
95. Khanam S, Sharma S, Pathak S. Lethal and Nonlethal Murine Malarial Infections Differentially Affect Apoptosis, Proliferation, and CD8 Expression on Thymic T Cells. Parasite Immunol (2015) 37(7):349-61. doi: 10.1111/ pim. 12197

96. Chen AL, Sun X, Wang W, Liu JF, Zeng X, Qiu JF, et al. Activation of the Hypothalamic-Pituitary-Adrenal (HPA) Axis Contributes to the Immunosuppression of Mice Infected With Angiostrongylus Cantonensis. J Neuroinflamm (2016) 13(1):266. doi: 10.1186/s12974-016-0743-Z

97. Liu Z, Su DM, Yu ZL, Wu F, Liu RF, Luo SQ, et al. Soluble Antigens From the Neurotropic Pathogen Angiostrongylus Cantonensis Directly Induce Thymus Atrophy in a Mouse Model. Oncotarget (2017) 8(30):48575-90. doi: 10.18632/oncotarget.17836

98. Wellhausen SR, Boros DL. Atrophy of the Thymic Cortex in Mice With Granulomatous Schistosomiasis Mansoni. Infect Immun (1982) 35(3):10639. doi: 10.1128/iai.35.3.1063-1069.1982

99. Li N, Ji PY, Song LG, Lei JX, Lv ZY, Wu ZD, et al. The Expression of Molecule CD28 and CD38 on CD4 ${ }^{+} / \mathrm{CD}^{+} \mathrm{T}$ Lymphocytes in Thymus and Spleen Elicited by Schistosoma Japonicum Infection in Mice Model. Parasitol Res (2015) 114(8):3047-58. doi: 10.1007/s00436-015-4507-y

100. Kawabata M, Hosaka Y, Kumada M, Matsui N, Kobayakawa T. Thymocytotoxic Autoantibodies Found in Mice Infected With Schistosoma Japonicum. Infect Immun (1981) 32(2):438-42. doi: 10.1128/ iai.32.2.438-442.1981

101. Brito VN, Souto PC, Cruz-Höfling MA, Ricci LC, Verinaud L. Thymus Invasion and Atrophy Induced by Paracoccidioides Brasiliensis in BALB/c Mice. Med Mycol (2003) 41(2):83-7. doi: 10.1080/mmy.41.2.83.87

102. Di Gangi R, Alves da Costa T, Thomé R, Peron G, Burger E, Verinaud L. Paracoccidioides Brasiliensis Infection Promotes Thymic Disarrangement and Premature Egress of Mature Lymphocytes Expressing Prohibitive Tcrs. BMC Infect Dis (2016) 16:209. doi: 10.1186/s12879-016-1561-8

103. Alves da Costa T, Di Gangi R, Thomé R, Barreto Felisbino M, Pires Bonfanti A, Lumi Watanabe Ishikawa L, et al. Severe Changes in Thymic Microenvironment in a Chronic Experimental Model of Paracoccidioidomycosis. PloS One (2016) 11 (10):e0164745. doi: 10.1371/journal.pone.0164745

104. Sutton P, Newcombe NR, Waring P, Müllbacher A. In Vivo Immunosuppressive Activity of Gliotoxin, a Metabolite Produced by Human Pathogenic Fungi. Infect Immun (1994) 62(4):1192-8. doi: 10.1128/IAI.62.4.1192-1198.1994

105. Islam Z, Nagase M, Yoshizawa T, Yamauchi K, Sakato N. T-2 Toxin Induces Thymic Apoptosis In Vivo in Mice. Toxicol Appl Pharmacol (1998) 148 (2):205-14. doi: 10.1006/taap.1997.8338

106. Alvarez F, Villena A, Zapata A, Razquin B. Histopathology of the Thymus in Saprolegnia-infected Wild Brown Trout, Salmo Trutta L. Vet Immunol Immunopathol (1995) 47(1-2):163-72. doi: 10.1016/0165-2427(94)05384-5

107. Lv QZ, Li DD, Han H, Yang YH, Duan JL, Ma HH, et al. Priming With FLO8-deficient Candida Albicans Induces Th1-biased Protective Immunity Against Lethal Polymicrobial Sepsis. Cell Mol Immunol (2020) 5:1-14. doi: 10.1038/s41423-020-00576-6

108. Li Y, Wang G, Liu Y, Tu Y, He Y, Wang Z, et al. Identification of Apoptotic Cells in the Thymus of Piglets Infected With Highly Pathogenic Porcine Reproductive and Respiratory Syndrome Virus. Virus Res (2014) 189:29-33. doi: 10.1016/j.virusres.2014.04.011

109. Stadejek T, Stankevicius A, Murtaugh MP, Oleksiewicz MB. Molecular Evolution of PRRSV in Europe: Current State of Play. Vet Microbiol (2013) 165(1-2):21-8. doi: 10.1016/j.vetmic.2013.02.029. Cited in: Pubmed

110. Karniychuk UU, Geldhof M, Vanhee M, Van Doorsselaere J, Saveleva TA, Nauwynck HJ. Pathogenesis and Antigenic Characterization of a New East European Subtype 3 Porcine Reproductive and Respiratory Syndrome Virus Isolate. BMC Vet Res (2010) 6:30. doi: 10.1186/1746-6148-6-30

111. Feng WH, Tompkins MB, Xu JS, Brown TT, Laster SM, Zhang HX, et al. Thymocyte and Peripheral Blood T Lymphocyte Subpopulation Changes in Piglets Following In Utero Infection With Porcine Reproductive and Respiratory Syndrome Virus. Virology (2002) 302(2):363-72. doi: 10.1006/viro.2002.1650

112. Wang G, He Y, Tu Y, Liu Y, Zhou EM, Han Z, et al. Comparative Analysis of Apoptotic Changes in Peripheral Immune Organs and Lungs Following Experimental Infection of Piglets With Highly Pathogenic and Classical Porcine Reproductive and Respiratory Syndrome Virus. Virol J (2014) 11:2. doi: $10.1186 / 1743-422 x-11-2$ 
113. Wang G, Yu Y, Tu Y, Li Y, Tong J, Zhang C, et al. Characterizing the Thymic Lesions in Piglets Infected With Attenuated Strains of Highly Pathogenic Porcine Reproductive and Respiratory Syndrome Virus. Vet Immunol Immunopathol (2015) 168(3-4):258-61. doi: 10.1016/j.vetimm.2015.10.007

114. Ogno G, Rodriguez-Gomez IM, Canelli E, Ruedas-Torres I, Alvarez B, Dominguez J, et al. Impact of PRRSV Strains of Different In Vivo Virulence on the Macrophage Population of the Thymus. Vet Microbiol (2019) 232:137-45. doi: 10.1016/j.vetmic.2019.04.016

115. Butler JE, Sinkora M, Wang G, Stepanova K, Li Y, Cai X. Perturbation of Thymocyte Development Underlies the PRRS Pandemic: A Testable Hypothesis. Front Immunol (2019) 10:1077. doi: 10.3389/fimmu.2019.01077

116. Kolte L, Rosenfeldt V, Vang L, Jeppesen D, Karlsson I, Ryder LP, et al. Reduced Thymic Size But No Evidence of Impaired Thymic Function in Uninfected Children Born to Human Immunodeficiency Virus-Infected Mothers. Pediatr Infect Dis J (2011) 30(4):325-30. doi: 10.1097/INF.0b013e3182019bc3

117. Gimeno IM, Witter RL, Cortes AL, Reed WM. Replication Ability of Three Highly Protective Marek's Disease Vaccines: Implications in Lymphoid Organ Atrophy and Protection. Avian Pathol (2011) 40(6):573-9. doi: 10.1080/03079457.2011.617725

118. Lee LF, Heidari M, Zhang H, Lupiani B, Reddy SM, Fadly A. Cell Culture Attenuation Eliminates rMd5DeltaMeq-induced Bursal and Thymic Atrophy and Renders the Mutant Virus as an Effective and Safe Vaccine Against Marek's Disease. Vaccine (2012) 30(34):5151-8. doi: 10.1016/j.vaccine.2012.05.043

119. Lee LF, Kreager K, Heidari M, Zhang H, Lupiani B, Reddy SM, et al. Properties of a Meq-Deleted Rmd5 Marek's Disease Vaccine: Protection Against Virulent MDV Challenge and Induction of Lymphoid Organ Atrophy are Simultaneously Attenuated by Serial Passage In Vitro. Avian Dis (2013) 57(2 Suppl):491-7. doi: 10.1637/10388-092612-Reg.1

120. Yilmaz H, Turan N, Ozgur NY, Helps CR, Akay. Detection of Chicken Anemia Virus DNA in the Thymus of Naturally Infected Chicks in Turkey. Avian Dis (2001) 45(2):529-33. doi: 10.2307/1593000

121. Kizaki H, Suzuki K, Tadakuma T, Ishimura Y. Adenosine ReceptorMediated Accumulation of Cyclic AMP-induced T-Lymphocyte Death Through Internucleosomal DNA Cleavage. J Biol Chem (1990) 265 (9):5280-4. doi: 10.1016/S0021-9258(19)34118-3

122. Nashar TO, Williams NA, Hirst TR. Cross-Linking of Cell Surface Ganglioside GM1 Induces the Selective Apoptosis of Mature CD8+ T Lymphocytes. Int Immunol (1996) 8(5):731-6. doi: 10.1093/intimm/8.5.731

123. Mocchegiani E, Santarelli L, Costarelli L, Cipriano C, Muti E, Giacconi R, et al. Plasticity of Neuroendocrine-Thymus Interactions During Ontogeny and Ageing: Role of Zinc and Arginine. Ageing Res Rev (2006) 5(3):281-309. doi: 10.1016/j.arr.2006.06.001

124. Chantranupong L, Scaria SM, Saxton RA, Gygi MP, Shen K, Wyant GA, et al. The CASTOR Proteins Are Arginine Sensors for the mTORC1 Pathway. Cell (2016) 165(1):153-64. doi: 10.1016/j.cell.2016.02.035

125. Keating R, McGargill MA. Mtor Regulation of Lymphoid Cells in Immunity to Pathogens. Front Immunol (2016) 7:180. doi: 10.3389/fimmu.2016.00180

126. Das P, Lahiri A, Lahiri A, Chakravortty D. Modulation of the Arginase Pathway in the Context of Microbial Pathogenesis: A Metabolic Enzyme Moonlighting as an Immune Modulator. PloS Pathog (2010) 6(6):e1000899. doi: 10.1371/journal.ppat.1000899

127. Napolitano LA, Lo JC, Gotway MB, Mulligan K, Barbour JD, Schmidt D, et al. Increased Thymic Mass and Circulating Naive CD4 T Cells in HIV-1infected Adults Treated With Growth Hormone. Aids (2002) 16(8):1103-11. doi: 10.1097/00002030-200205240-00003

128. Wang D, Muller N, McPherson KG, Reichardt HM. Glucocorticoids Engage Different Signal Transduction Pathways to Induce Apoptosis in Thymocytes and Mature T Cells. J Immunol (2006) 176(3):1695-702. doi: 10.4049/ jimmunol.176.3.1695

129. El-Shaikh KA, Gabry MS, Othman GA. Recovery of Age-Dependent Immunological Deterioration in Old Mice by Thyroxine Treatment. J Anim Physiol Anim Nutr (Berl) (2006) 90(5-6):244-54. doi: 10.1111/ j.1439-0396.2005.00602.x

130. Hareramadas B, Rai U. Cellular Mechanism of Estrogen-Induced Thymic Involution in Wall Lizard: Caspase-Dependent Action. J Exp Zool A Comp Exp Biol (2006) 305(5):396-409. doi: 10.1002/jez.a.260

131. De Mello-Coelho V, Savino W, Postel-Vinay MC, Dardenne M. Role of Prolactin and Growth Hormone on Thymus Physiology. Dev Immunol (1998) 6(3-4):317-23. doi: 10.1155/1998/89782. Cited in: Pubmed
132. Merrick JC, Edelson BT, Bhardwaj V, Swanson PE, Unanue ER. Lymphocyte Apoptosis During Early Phase of Listeria Infection in Mice. Am J Pathol (1997) 151(3):785-92.

133. Ito M, Nishiyama K, Hyodo S, Shigeta S, Ito T. Weight Reduction of Thymus and Depletion of Lymphocytes of T-dependent Areas in Peripheral Lymphoid Tissues of Mice Infected With Francisella Tularensis. Infect Immun (1985) 49(3):812-8. doi: 10.1128/IAI.49.3.812-818.1985

134. Nguyen T, Waseem M. Chagas Disease (American Trypanosomiasis). Treasure Island (FL: StatPearls (2020). StatPearls Publishing Copyright () 2020, StatPearls Publishing LLC.

135. Colato RP, Brazão V, do Vale GT, Santello FH, Sampaio PA, Tirapelli CR, et al. Cytokine Modulation, Oxidative Stress and Thymic Dysfunctions: Role of Age-Related Changes in the Experimental Trypanosoma Cruzi Infection: Age-related Thymic Dysfunctions and Trypanosoma Cruzi Infection. Cytokine (2018) 111:88-96. doi: 10.1016/j.cyto.2018.08.004

136. Beltran-Hortelano I, Alcolea V, Font M, Pérez-Silanes S. The Role of Imidazole and Benzimidazole Heterocycles in Chagas Disease: A Review. Eur J Med Chem (2020) 206:112692. doi: 10.1016/j.ejmech.2020.112692

137. Perez AR, Morrot A, Carvalho VF, de Meis J, Savino W. Role of Hormonal Circuitry Upon T Cell Development in Chagas Disease: Possible Implications on T Cell Dysfunctions. Front Endocrinol (Lausanne) (2018) 9:334. doi: 10.3389/fendo.2018.00334

138. Morrot A, Terra-Granado E, Perez AR, Silva-Barbosa SD, Milicevic NM, Farias-de-Oliveira DA, et al. Chagasic Thymic Atrophy Does Not Affect Negative Selection But Results in the Export of Activated CD4+CD8+ T Cells in Severe Forms of Human Disease. PloS Negl Trop Dis (2011) 5(8):e1268. doi: 10.1371/journal.pntd.0001268

139. Matloubian M, Lo CG, Cinamon G, Lesneski MJ, Xu Y, Brinkmann V, et al. Lymphocyte Egress From Thymus and Peripheral Lymphoid Organs is Dependent on S1P Receptor 1. Nature (2004) 427(6972):355-60. doi: 10.1038/nature02284

140. Lepletier A, de Almeida L, Santos L, da Silva Sampaio L, Paredes B, Gonzalez FB, et al. Early Double-Negative Thymocyte Export in Trypanosoma Cruzi Infection is Restricted by Sphingosine Receptors and Associated With Human Chagas Disease. PloS Negl Trop Dis (2014) 8(10):e3203. doi: 10.1371/journal.pntd.0003203

141. Nardy AF, Luiz da Silva Filho J, Perez AR, de Meis J, Farias-de-Oliveira DA, Penha L, et al. Trans-Sialidase From Trypanosoma Cruzi Enhances the Adhesion Properties and Fibronectin-Driven Migration of Thymocytes. Microbes Infect (2013) 15(5):365-74. doi: 10.1016/j.micinf.2013.02.003

142. Farias-de-Oliveira DA, Cotta-de-Almeida V, Villa-Verde DM, Riederer I, Meis J, Savino W. Fibronectin Modulates Thymocyte-Thymic Epithelial Cell Interactions Following Trypanosoma Cruzi Infection. Mem Inst Oswaldo Cruz (2013) 108(7):825-31. doi: 10.1590/0074-0276130071

143. Silva-Monteiro E, Reis Lorenzato L, Kenji Nihei O, Junqueira M, Rabinovich GA, Hsu DK, et al. Altered Expression of Galectin-3 Induces Cortical Thymocyte Depletion and Premature Exit of Immature Thymocytes During Trypanosoma Cruzi Infection. Am J Pathol (2007) 170(2):546-56. doi: 10.2353/ajpath.2007.060389

144. Gonzalez FB, Calmon-Hamaty F, No Seara Cordeiro S, Fernandez Bussy R, Spinelli SV, D'Attilio L, et al. Trypanosoma Cruzi Experimental Infection Impacts on the Thymic Regulatory T Cell Compartment. PloS Negl Trop Dis (2016) 10(1):e0004285. doi: 10.1371/journal.pntd.0004285

145. Gonzalez FB, Villar SR, Fernandez Bussy R, Martin GH, Perol L, Manarin R, et al. Immunoendocrine Dysbalance During Uncontrolled T. Cruzi Infection is Associated With the Acquisition of a Th-1-like Phenotype by Foxp3(+) T Cells. Brain Behav Immun (2015) 45:219-32. doi: 10.1016/j.bbi.2014.11.016

146. Besedovsky HO, del Rey A. Immune-Neuro-Endocrine Interactions: Facts and Hypotheses. Endocr Rev (1996) 17(1):64-102. doi: 10.1210/edrv-17-1-64

147. Farias-de-Oliveira DA, Villa-Verde DM, Nunes Panzenhagen PH, Silva dos Santos D, Berbert LR, Savino W, et al. Caspase-8 and Caspase-9 Mediate Thymocyte Apoptosis in Trypanosoma Cruzi Acutely Infected Mice. J Leukoc Biol (2013) 93(2):227-34. doi: 10.1189/jlb.1211589

148. Bonney KM, Engman DM. Autoimmune Pathogenesis of Chagas Heart Disease: Looking Back, Looking Ahead. Am J Pathol (2015) 185(6):1537-47. doi: 10.1016/j.ajpath.2014.12.023

149. Perez AR, Roggero E, Nicora A, Palazzi J, Besedovsky HO, Del Rey A, et al. Thymus Atrophy During Trypanosoma Cruzi Infection is Caused by an 
Immuno-Endocrine Imbalance. Brain Behav Immun (2007) 21(7):890-900. doi: 10.1016/j.bbi.2007.02.004

150. Roggero E, Perez AR, Tamae-Kakazu M, Piazzon I, Nepomnaschy I, Besedovsky HO, et al. Endogenous Glucocorticoids Cause Thymus Atrophy But are Protective During Acute Trypanosoma Cruzi Infection. J Endocrinol (2006) 190(2):495-503. doi: 10.1677/joe.1.06642

151. Krishnan N, Thellin O, Buckley DJ, Horseman ND, Buckley AR. Prolactin Suppresses Glucocorticoid-Induced Thymocyte Apoptosis In Vivo. Endocrinology (2003) 144(5):2102-10. doi: 10.1210/en.2003-0053

152. Biswas R, Roy T, Chattopadhyay U. Prolactin Induced Reversal of Glucocorticoid Mediated Apoptosis of Immature Cortical Thymocytes is Abrogated by Induction of Tumor. J Neuroimmunol (2006) 171(1-2):12034. doi: 10.1016/j.jneuroim.2005.09.014

153. Savino W. Endocrine Immunology of Chagas Disease. Front Horm Res (2017) 48:160-75. doi: 10.1159/000452914

154. Lepletier A, de Carvalho VF, Rodrigues e Silva PM, Villar S, Perez AR, Savino W, et al. Trypanosoma Cruzi Disrupts Thymic Homeostasis by Altering Intrathymic and Systemic Stress-Related Endocrine Circuitries. PloS Negl Trop Dis (2013) 7(11):e2470. doi: 10.1371/journal.pntd.0002470

155. Loria RM. Antiglucocorticoid Function of Androstenetriol. Psychoneuroendocrinology (1997) 22 Suppl 1:S103-8. doi: 10.1016/s0306-4530(97)00005-x

156. Hampl R, Vondra K. [Natural Antiglucocorticoids]. Vnitr Lek (2006) 52(10):973-8.

157. Chen Y, Qiao S, Tuckermann J, Okret S, Jondal M. Thymus-Derived Glucocorticoids Mediate Androgen Effects on Thymocyte Homeostasis. FASEB J (2010) 24(12):5043-51. doi: 10.1096/fj.10-168724

158. Mucci J, Mocetti E, Leguizamon MS, Campetella O. A Sexual Dimorphism in Intrathymic Sialylation Survey is Revealed by the Trans-Sialidase From Trypanosoma Cruzi. J Immunol (2005) 174(8):4545-50. doi: 10.4049/ jimmunol.174.8.4545

159. Filipin Mdel V, Caetano LC, Brazao V, Santello FH, Toldo MP, do Prado JCJr. DHEA and Testosterone Therapies in Trypanosoma Cruzi-Infected Rats are Associated With Thymic Changes. Res Vet Sci (2010) 89(1):98-103. doi: 10.1016/j.rvsc.2010.01.016

160. Engdahl C, Lagerquist MK, Stubelius A, Andersson A, Studer E, Ohlsson C, et al. Role of Androgen and Estrogen Receptors for the Action of Dehydroepiandrosterone (DHEA). Endocrinology (2014) 155(3):889-96. doi: 10.1210/en.2013-1561

161. Linhares-Lacerda L, Palu CC, Ribeiro-Alves M, Paredes BD, Morrot A, Garcia-Silva MR, et al. Differential Expression of microRNAs in Thymic Epithelial Cells From Trypanosoma Cruzi Acutely Infected Mice: Putative Role in Thymic Atrophy. Front Immunol (2015) 6:428. doi: 10.3389/ fimmu.2015.00428

162. Acuna SM, Floeter-Winter LM, Muxel SM. Micrornas: Biological Regulators in Pathogen-Host Interactions. Cells (2020) 9(1):113. doi: 10.3390/ cells9010113. Cited in: Pubmed

163. Lévêque MF, Lachaud L, Simon L, Battery E, Marty P, Pomares C. Place of Serology in the Diagnosis of Zoonotic Leishmaniases With a Focus on Visceral Leishmaniasis Due to Leishmania Infantum. Front Cell Infect Microbiol (2020) 10:67. doi: 10.3389/fcimb.2020.00067

164. de Koning-Ward TF, Dixon MW, Tilley L, Gilson PR. Plasmodium Species: Master Renovators of Their Host Cells. Nat Rev Microbiol (2016) 14(8):494507. doi: $10.1038 /$ nrmicro.2016.79

165. Ashley EA, Pyae Phyo A, Woodrow CJ. Malaria. Lancet (2018) 391 (10130):1608-21. doi: 10.1016/s0140-6736(18)30324-6

166. Stephens R, Culleton RL, Lamb TJ. The Contribution of Plasmodium Chabaudi to Our Understanding of Malaria. Trends Parasitol (2012) 28 (2):73-82. doi: 10.1016/j.pt.2011.10.006

167. Carvalho LJ, Ferreira-da-cruz MF, Daniel-Ribeiro CT, Pelajo-Machado M, Lenzi HL. Plasmodium Berghei ANKA Infection Induces Thymocyte Apoptosis and Thymocyte Depletion in CBA Mice. Mem Inst Oswaldo Cruz (2006) 101(5):523-8. doi: 10.1590/s0074-02762006000500007

168. Pinna RA, Silva-Dos-Santos D, Perce-da-Silva DS, Oliveira-Ferreira J, VillaVerde DM, De Luca PM, et al. Malaria-Cutaneous Leishmaniasis CoInfection: Influence on Disease Outcomes and Immune Response. Front Microbiol (2016) 7:982. doi: 10.3389/fmicb.2016.00982

169. Wang QP, Lai DH, Zhu XQ, Chen XG, Lun ZR. Human Angiostrongyliasis. Lancet Infect Dis (2008) Oct8(10):621-30. doi: 10.1016/s1473-3099(08) 70229-9
170. Sohal RJ, Gilotra TS, Lui F. Angiostrongylus Cantonensis (Angiostrongliasis). (2020) StatPearls. Treasure Island (FL): StatPearls Publishing.

171. Schwartz C, Fallon PG. Schistosoma "Eggs-Iting" the Host: Granuloma Formation and Egg Excretion. Front Immunol (2018) 9:2492. doi: 10.3389/ fimmu.2018.02492

172. McManus DP, Dunne DW, Sacko M, Utzinger J, Vennervald BJ, Zhou XN. Schistosomiasis. Nat Rev Dis Primers (2018) 4(1):13. doi: 10.1038/s41572018-0013-8

173. Gryseels B. Schistosomiasis. Infect Dis Clin North Am (2012) 26(2):383-97. doi: 10.1016/j.idc.2012.03.004

174. Zhang J, Wang Y, Aili A, Sun X, Pang X, Ge Q, et al. Aire-Th1 Biased Progressive Autoimmunity in Aged Deficient Mice Accelerated Thymic Epithelial Cell Senescence. Aging Dis (2019) 10(3):497-509. doi: 10.14336/ ad.2018.0608

175. Majumdar S, Adiga V, Raghavan A, Rananaware SR, Nandi D. Comparative Analysis of Thymic Subpopulations During Different Modes of Atrophy Identifies the Reactive Oxygen Species Scavenger, $\mathrm{N}$-acetyl Cysteine, to Increase the Survival of Thymocytes During Infection-Induced and Lipopolysaccharide-Induced Thymic Atrophy. Immunology (2019) 157 (1):21-36. doi: 10.1111/imm.13043

176. Schwabe R, Luedde T. Apoptosis and Necroptosis in the Liver: A Matter of Life and Death. Nat Rev Gastroenterol Hepatol (2018) 15(12):738-52. doi: 10.1038/s41575-018-0065-y

177. Wang K, Shi Y, Denhardt D. Osteopontin Regulates Hindlimb-UnloadingInduced Lymphoid Organ Atrophy and Weight Loss by Modulating Corticosteroid Production. Proc Natl Acad Sci U States America (2007) 104(37):14777-82. doi: 10.1073/pnas.0703236104

178. Guha I, Bhuniya A, Nandi P, Dasgupta S, Sarkar A, Saha A, et al. Neem Leaf Glycoprotein Reverses Tumor-Induced and Age-Associated Thymic Involution to Maintain Peripheral CD8 T Cell Pool. Immunotherapy (2020) 12(11):799-818. doi: 10.2217/imt-2019-0168

179. Zhang J, Li S, Li L, Li M, Guo C, Yao J, et al. Exosome and Exosomal microRNA: Trafficking, Sorting, and Function. Genomics Proteomics Bioinf (2015) 13(1):17-24. doi: 10.1016/j.gpb.2015.02.001

180. Coakley G, Buck AH, Maizels RM. Host Parasite communications-Messages From Helminths for the Immune System: Parasite Communication and CellCell Interactions. Mol Biochem Parasitol (2016) 208(1):33-40. doi: 10.1016/ j.molbiopara.2016.06.003

181. Silverman JM, Clos J, Horakova E, Wang AY, Wiesgigl M, Kelly I, et al. Leishmania Exosomes Modulate Innate and Adaptive Immune Responses Through Effects on Monocytes and Dendritic Cells. J Immunol (2010) 185 (9):5011-22. doi: 10.4049/jimmunol.1000541

182. Szempruch AJ, Sykes SE, Kieft R, Dennison L, Becker AC, Gartrell A, et al. Extracellular Vesicles From Trypanosoma Brucei Mediate Virulence Factor Transfer and Cause Host Anemia. Cell (2016) 164(1-2):246-57. doi: 10.1016/ j.cell.2015.11.051. Cited in: Pubmed

183. Twu O, de Miguel N, Lustig G, Stevens GC, Vashisht AA, Wohlschlegel JA, et al. Trichomonas Vaginalis Exosomes Deliver Cargo to Host Cells and Mediate Host:Parasite Interactions. PloS Pathog (2013) 9(7):e1003482. doi: 10.1371/journal.ppat.1003482

184. Geiger A, Hirtz C, Bécue T, Bellard E, Centeno D, Gargani D, et al. Exocytosis and Protein Secretion in Trypanosoma. BMC Microbiol (2010) Jan 2610:20. doi: 10.1186/1471-2180-10-20

185. Atyame Nten CM, Sommerer N, Rofidal V, Hirtz C, Rossignol M, Cuny G, et al. Excreted/Secreted Proteins From Trypanosome Procyclic Strains. J BioMed Biotechnol (2010) 2010:212817. doi: 10.1155/2010/212817

186. Zhu L, Liu J, Dao J, Lu K, Li H, Gu H, et al. Molecular Characterization of S. Japonicum Exosome-Like Vesicles Reveals Their Regulatory Roles in Parasite-Host Interactions. Sci Rep (2016) 6:25885. doi: 10.1038/srep25885

187. Garcia-Silva MR, Cabrera-Cabrera F, das Neves RF, Souto-Padrón T, de Souza W, Cayota A. Gene Expression Changes Induced by Trypanosoma Cruzi Shed Microvesicles in Mammalian Host Cells: Relevance of tRNAderived Halves. BioMed Res Int (2014) 2014:305239. doi: 10.1155/2014/ 305239

188. Wang L, Li Z, Shen J, Liu Z, Liang J, Wu X, et al. Exosome-Like Vesicles Derived by Schistosoma Japonicum Adult Worms Mediates M1 Type Immune- Activity of Macrophage. Parasitol Res (2015) 114(5):1865-73. doi: $10.1007 / \mathrm{s} 00436-015-4373-7$ 
189. Oliveira DL, Freire-de-Lima CG, Nosanchuk JD, Casadevall A, Rodrigues ML, Nimrichter L. Extracellular Vesicles From Cryptococcus Neoformans Modulate Macrophage Functions. Infect Immun (2010) 78(4):1601-9. doi: 10.1128/iai.01171-09

190. Buck AH, Coakley G, Simbari F, McSorley HJ, Quintana JF, Le Bihan T, et al. Exosomes Secreted by Nematode Parasites Transfer Small RNAs to Mammalian Cells and Modulate Innate Immunity. Nat Commun (2014) 5:5488. doi: $10.1038 /$ ncomms6488

191. Majumdar S, Nandi D. Thymic Atrophy: Experimental Studies and Therapeutic Interventions. Scand J Immunol (2018) 87(1):4-14. doi: 10.1111/sji.12618

192. Müller F, Svardal AM, Nordoy I, Berge RK, Aukrust P, Frøland SS. Virological and Immunological Effects of Antioxidant Treatment in Patients With HIV Infection. Eur J Clin Invest (2000) 30(10):905-14. doi: 10.1046/j.1365-2362.2000.00727.x

193. Liang C, Liao J, Deng Z, Song C, Zhang J, Zabeau L, et al. Leptin Attenuates Lipopolysaccharide-Induced Apoptosis of Thymocytes Partially Via DownRegulation of cPLA2 and P38 MAPK Activation. Int Immunopharmacol (2013) 15(3):620-7. doi: 10.1016/j.intimp.2013.01.014

194. Brazao V, Colato RP, Santello FH, Vale GTD, Gonzaga NA, Tirapelli CR, et al. Effects of Melatonin on Thymic and Oxidative Stress Dysfunctions During Trypanosoma Cruzi Infection. J Pineal Res (2018) 65(3):e12510. doi: $10.1111 /$ jpi.12510

195. Prattichizzo F, Giuliani A, Sabbatinelli J, Mensà E, De Nigris V, La Sala L, et al. Extracellular Vesicles Circulating in Young Organisms Promote Healthy Longevity. J Extracell Vesicles (2019) 8(1):1656044. doi: 10.1080/ 20013078.2019.1656044

196. Wang W, Wang L, Ruan L, Oh J, Dong X, Zhuge Q, et al. Extracellular Vesicles Extracted From Young Donor Serum Attenuate Inflammaging Via Partially Rejuvenating Aged T-cell Immunotolerance. FASEB J (2018) 21 (11):32. doi: 10.1096/fj.201800059R

197. Banfai K, Garai K, Ernszt D, Pongracz JE, Kvell K. Transgenic Exosomes for Thymus Regeneration. Front Immunol (2019) 10:862. doi: 10.3389/ fimmu.2019.00862
198. Leposavić G, Ugresić N, Pejcić-Karapetrović B, Mićić M. Castration of Sexually Immature Rats Affects Sympathetic Innervation of the Adult Thymus. Neuroimmunomodulation (2000) 7(2):59-67. doi: 10.1159/ 000026421

199. Slota C, Shi A, Chen G, Bevans M, Weng NP. Norepinephrine Preferentially Modulates Memory CD8 T Cell Function Inducing Inflammatory Cytokine Production and Reducing Proliferation in Response to Activation. Brain Behav Immun (2015) 46:168-79. doi: 10.1016/j.bbi.2015.01.015

200. Kvetnanský R, Pacák K, Fukuhara K, Viskupic E, Hiremagalur B, Nankova B, et al. Sympathoadrenal System in Stress. Interaction With the HypothalamicPituitary-Adrenocortical System. Ann N Y Acad Sci (1995) 771:131-58. doi: 10.1111/j.1749-6632.1995.tb44676.x

201. Leander S, Håkanson R, Rosell S, Folkers K, Sundler F, Tornqvist K. A Specific Substance P Antagonist Blocks Smooth Muscle Contractions Induced by non-Cholinergic, non-Adrenergic Nerve Stimulation. Nature (1981) 294(5840):467-9. doi: 10.1038/294467a0

202. Lucchese A. Streptococcus Mutans Antigen I/II and Autoimmunity in Cardiovascular Diseases. Autoimmun Rev (2017) 16(5):456-60. doi: 10.1016/j.autrev.2017.03.009

203. Novotna M, Podzimek S, Broukal Z, Lencova E, Duskova J. Periodontal Diseases and Dental Caries in Children With Type 1 Diabetes Mellitus. Mediators Inflammation (2015) 2015:379626. doi: 10.1155/2015/379626

Conflict of Interest: The authors declare that the research was conducted in the absence of any commercial or financial relationships that could be construed as a potential conflict of interest.

Copyright (c) 2021 Luo, Xu, Qian and Sun. This is an open-access article distributed under the terms of the Creative Commons Attribution License (CC BY). The use, distribution or reproduction in other forums is permitted, provided the original author(s) and the copyright owner(s) are credited and that the original publication in this journal is cited, in accordance with accepted academic practice. No use, distribution or reproduction is permitted which does not comply with these terms. 